\title{
Did Behavioral Mutual Funds Exploit Market Inefficiencies During or After the Financial Crisis?
}

\author{
Nikolaos Philippas* \\ University of Piraeus, Greece
}

This study examines the performance of mutual funds that employ investment strategies based on the principles of behavioral finance, collectively known as "behavioral mutual funds". A series of performance measures is employed in order to test whether behavioral mutual funds outperform the stock market, their benchmarks or passively managed index funds, using monthly data for the period January 2007-March 2013. Results from the full sample and subperiod analysis show that behavioral mutual funds actually exhibited poor performance, both during the recent financial crisis and in its aftermath, rejecting the conjecture that the crisis period would provide an ideal environment for their strategies to be profitable by exploiting market inefficiencies and investors' behavioral biases. (JEL: G15)

Keywords: behavioral mutual funds, financial crisis, market inefficiencies, performance evaluation

\section{Introduction}

The recent global crisis was characterized by a series of unprecedented events in the financial markets and the banking sector showing that asset prices can deviate from their fundamental values for a prolonged period and that market forces may be too slow or even incapable of restoring equilibrium (see Brunnermeier, 2009, for a detailed account of the crisis events). Brunnermeier (2001) has analyzed how asymmetric information and herding behavior in periods of financial stress and turmoil can lead to bubbles and crashes harming the price discovery mechanism of the

\footnotetext{
* Department of Business Administration, University of Piraeus, Greece. E-mail: philipas@unipi.gr.

(Multinational Finance Journal, 2014, vol. 18, no. 1/2, pp. 85-138)

(C) Multinational Finance Society, a nonprofit corporation. All rights reserved. DOI: $10.17578 / 18-1 / 2-3$
} 
market. Leading to the same conclusions, Gromb and Vayanos (2010) have shown that assets' mispricings may be persistent due to a series of frictions that prevent arbitrageurs from eliminating them. Among these frictions, Constantinides (1997) focused on the impact of the transaction costs on asset pricing and Shin (2010) and Brunnermeier and Pedersen (2009) particularly emphasize the role of liquidity risk that financially constrained intermediaries face.

Another strand of the literature attempts to explain the same market phenomena resorting to the generic term "investor sentiment", introduced by DeLong et al. (1990). As Baker and Wurgler (2007, p. 129) note: "investor sentiment, defined broadly, is a belief about future cash flows and investment risks that is not justified by the facts in hand". This concept has given rise to a voluminous literature in "behavioral finance" that borrows insights from cognitive psychology to examine how investors' biases can affect their financial decision making and, in aggregation, the formation of market prices (see Shefrin, 2000 for an introduction). Apart from enhancing our understanding of extreme phenomena in financial markets, the concept of investor sentiment has recently proved quite useful for asset pricing too (see Brown and Cliff, 2005, Baker and Wurgler, 2006 and Kumar and Lee, 2006).

The appeal of the investor sentiment approach led to the introduction of mutual funds that follow investment strategies trying to exploit behavioral biases and market anomalies for the benefit of their shareholders. These are collectively termed as "behavioral mutual funds". However, this market development also poses a real challenge to this investment approach, allowing us to test whether it actually yields superior returns when it is implemented by professional fund managers. This is the aim of this study. In particular, the paper presents a series of raw as well as risk-adjusted performance measures to examine whether behavioral funds outperform their benchmark indices, market returns and passive mutual funds (index funds, ETFs), using monthly data for the period January 2007-March 2013. Moreover, a subperiod analysis is conducted, distinguishing between the crisis period, January 2007-December 2009 and the post-crisis period, January 2010-March 2013. We conjecture that persistent mispricings during the crisis period, which were caused by "limits to arbitrage" as previously discussed, would be more difficult to exploit by institutional investors relative to opportunistic mispricings due to investors' behavioral biases arising in the aftermath of the crisis. 
The present study contributes to the limited existing literature on the performance evaluation of behavioral mutual funds in a series of ways. This paper is the first to examine how these behavioral funds performed during and after the recent financial crisis period, providing an ideal environment to test the conjecture that their strategies can exploit market inefficiencies and investors' behavioral biases. Secondly, a larger number of funds is employed relative to previous studies in the literature (see Wright, Banerjee and Boney, 2006, and Reinhart and Brennan, 2007), who reported inconclusive evidence due to the very small number of funds and short time period they examined. Thirdly, in contrast to the recent study of Santoni and Kelshiker (2010), who provide mainly descriptive statistics on funds' performance, we use a plethora of sophisticated performance evaluation measures that can formally test the existence of superior managerial performance adjusting for common risk factors and using different benchmark indices as well as for their market timing ability.

The larger number of funds and the use of various performance measures allows us to reach the following conclusions. The results indicate that behavioral funds' managers neither outperformed their benchmarks nor they exhibited market timing ability during the examined sample period. To the contrary, economically and statistically significant underperformance is reported for a number of funds relative to the market and their benchmark indices. This evidence remains intact even when we distinguish between the crisis period and its aftermath. Moreover, there is no evidence that behavioral funds follow any particular investment style, such as size, value or momentum strategies.

The rest of the study is organized as follows. Section 2 provides a brief background on the global mutual fund industry and behavioral funds' sector. Section 3 contains the details regarding the dataset and the definitions of the performance measures. Section 4 presents and discusses the empirical results of the study, while section 5 concludes.

\section{Global fund industry and behavioral funds}

The importance of mutual funds in financial markets has dramatically risen over the past twenty five years, due to their unique benefits for individual investors (see Philippas and Tsionas, 2002, for a detailed discussion). The extensive variety of available mutual funds necessitates a comprehensive performance evaluation of mutual fund managers to 
identify whether fund managers actually add value in shareholder portfolios or they simply waste resources through the active management strategies they employ (Philippas and Tsionas, 2002).

Fund managers' ability to outperform the market has been a subject of debate during the last decades. Previous research indicates that, on average, traditional active mutual funds tend to underperform their passive benchmarks ${ }^{1}$ (see Babalos et al., 2012, for recent evidence). According to Wermers (2000), actively managed mutual funds do not succeed in outperforming the market on a risk-adjusted basis. In fact, high costs of actively managed U.S. equity mutual funds reduce returns below market's returns (see Fama and French, 2010). A comprehensive study by Bogle (2005) documented that the average equity net-of-expenses fund return for the period 1983-2003 did not exceed the corresponding market index return. This finding provides a rationale for the dramatic rise of indexing and low cost passive investment strategies.

Performance evaluation of behavioral funds is a relatively new field of research; it examines whether fund managers can actually exploit market inefficiencies as well as documented behavioral biases. In fact, as previous studies have identified, behavioral funds' strategies are not based on the classical portfolio theory but implicitly accept investors' irrational behavior and the possibility of abnormal returns by acknowledging potential market inefficiencies (see Reinhart and Brennan, 2007 and Santoni amd Kelshiker, 2010, for a discussion). As expected, behavioral funds do not explicitly state their particular investment strategies, since this is their comparative advantage relative to their competitors.

Reinhart and Brennan (2007) examined the performance of 9 behavioral mutual funds during the period 1997-2003; they also compared behavioral funds' performance with traditional mutual funds (in terms of premia, alphas, Sharpe ratios, Treynor ratios and information ratios) and showed that inefficiencies can actually improve portfolios' performance, mainly when examining large-cap behavioral funds. In the same spirit, Wright et al. (2006) examined the performance of 16 behavioral funds since their inception date, identifying their ability to attract investment flows. They found that even though behavioral funds as a group outperform S\&P 500 index funds, they did not deliver abnormal returns once they account for size, value and

1. Identifying the appropriate benchmark index is of particular importance in order to measure the performance of the fund managers (Tabner, 2009). 
momentum factors in line with the Fama-French 3-factor and Carhart 4-factor models; this is because behavioral funds exhibited a heavy loading on the value factor. More recently, Santoni and Kelshiker (2010) analyzed the performance of 31 international behavioral mutual funds from 1997 to 2003. These studies yielded mixed evidence regarding the funds' performance. This is because they examine a relatively small number of funds, using different and rather short sample periods. Moreover, with the exception of Wright et al. (2006), this mixed evidence can be attributed to the use of rather simple performance measures that fail to properly account for market risk as well as other common factors, such as size, value and momentum.

\section{Data and Methodology}

The study covers the recent global financial crisis period and its aftermath, i.e. the period from January 2007 to March 2013, and examines the performance of 22 US behavioral mutual funds using monthly returns. ${ }^{2}$ Table 1 provides the details of the funds used. To build our dataset, we firstly include the same funds that prior studies have used (see Reinhart and Brennan, 2007, Wright et al., 2006, 2008, and Santoni and Kelshiker, 2010). In addition to these funds, an extensive search on Bloomberg fund database was conducted in order to identify other funds that explicitly state in their prospectuses that they follow behavioral strategies. Moreover, two Index Funds (VFINXVanguard 500 Index Fund and FUSEX - Fidelity S\&P 500 Index Fund) and one ETF written on S\&P 500 (SPY - SPDR S\&P 500 ETF Trust) are employed as the most representative funds of passive management. These passive funds are used as a benchmark of comparison for behavioral funds. Data regarding market, funds' and benchmarks' returns were sourced from Bloomberg, Financial Industry Regulatory Authority, Lipper as well as individual mutual fund companies. Bloomberg is also the source for the funds' characteristics used in the cross-sectional analysis of their performance. Monthly returns for the market, risk free rate, size (SMB), value (HML) and momentum(UMD) factors are sourced from Kenneth French's online data library.

The analysis is conducted in two stages. Firstly, we estimate average

2. There is one more behavioral fund with inception date $8 / 9 / 2011$. Since we do not have enough observations to evaluate the funds' performance during the crisis period we exclude this fund from our sample. 







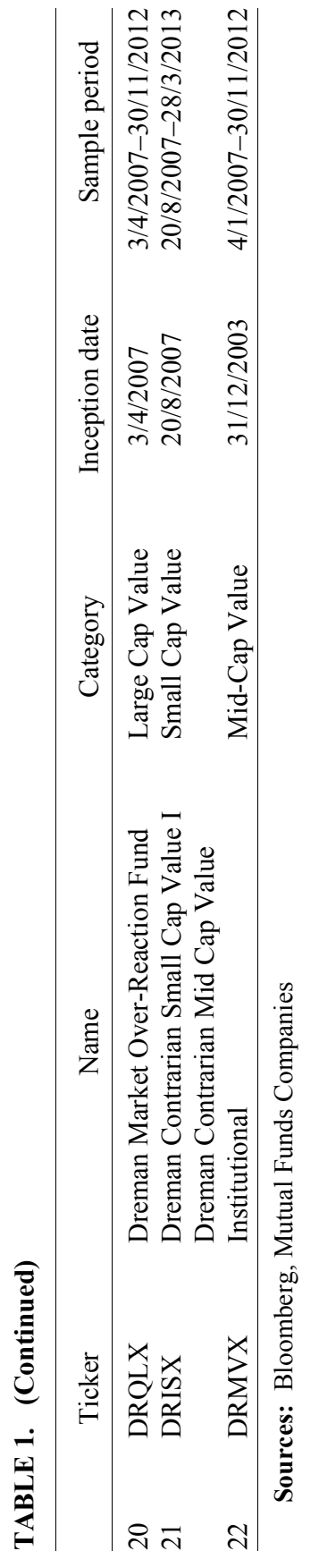


monthly returns as well as the standard deviation of returns and the beta coefficient of the funds from the Capital Asset Pricing Model (CAPM). Secondly, we employ several performance measures on a risk-adjusted basis. The most commonly used risk-adjusted performance measures are Sharpe (1966) and Treynor (1965) ratios that measure funds' reward (excess return) to variability captured either by standard deviation of returns or by beta coefficient. Sharpe ratio is defined as follows:

$$
\text { Sharpe Ratio }=\left(R_{P}-R_{f}\right) / s d_{p}
$$

where $R_{p}$ is the return of the portfolio/fund, $R_{f}$ is the risk free rate and $s d_{p}$ is the standard deviation of the mutual fund's returns (total risk). Treynor ratio is defined as follows:

$$
\text { Treynor Ratio }=\left(R_{p}-R_{f}\right) / \beta_{p}
$$

where $R_{p}$ is the return of the fund, $\mathrm{R}_{f}$ is the risk free rate and $\beta_{p}$ is the mutual fund's beta coefficient of systematic risk from the CAPM.

Apart from the simple risk-adjusted measures, we also estimate funds' abnormal return after accounting for several risk factors. The models used include the Jensen's model (1968), the Treynor and Mazuy's model (1966), as well as the Carhart's model (1997). Jensen (1968) estimated the following single factor model to measure portfolios' abnormal performance:

$$
R_{p t}-R_{f}=a_{p}+\beta_{p}\left(R_{m t}-R_{f}\right)+\varepsilon_{p t}
$$

where $R_{p t}$ is the return of the fund $p, R_{m t}$ is the return of the market portfolio, $\alpha_{p}$ is a measure of security selection ability (abnormal return), $\beta_{p}$ is the beta coefficient of the portfolio $p$ and $\varepsilon_{p t}$ is a random error.

Carhart (1997) added the well known momentum factor to the traditional Fama-French 3-factor model, providing an alternative measure for fund managers' selectivity skill (Carhart's alpha), as follows:

$$
\begin{gathered}
R_{p t}-R_{f}=\alpha_{p}+\beta_{p}\left(R_{m t}-R_{f}\right)+ \\
S_{P} S M B_{t}+h_{p} H M L+m_{p} U M D_{t}+\varepsilon_{p t}
\end{gathered}
$$


where $R_{m t}-R_{f} S M B_{t}$ and $H M L_{t}$ stand for the returns of Fama and French's factor-mimicking portfolios on the market, size and value, respectively, while $U M D_{t}$ is the return of Carhart's momentum factor.

The previous models for estimating abnormal performance do not capture a manager's potential market timing skill, which is also very important especially during periods of financial crisis. In fact, the funds' risk level is not expected to be constant because fund managers may shift their portfolios' risk composition according to their expectations about the direction of the market (bull/bear market). Treynor and Mazuy (1966) proposed a simple method that has been widely used in order to jointly identify potential stock selection (selecting the better performing stocks) and market timing (shift risk composition according to market conditions) abilities of the fund managers. Treynor and Mazuy (1966) added a quadratic term to equation (3) in order to test for potential fund manager's market timing ability. In this case, the fund return will be a nonlinear function of the market return as follows:

$$
R_{p t}-R_{f}=\alpha_{p}+\beta_{p}\left(R_{m t}-R_{f}\right)+c_{P}\left(R_{m t}-R_{f}\right)^{2}+\varepsilon_{p t}
$$

where all variables have been already defined. A positive and statistically significant value of coefficient $c_{p}$ indicates the existence of a positive market timing skill. In this case, the last term of the equation will make the characteristic line steeper as $R_{m}$ becomes greater. For robustness, we have also augmented the Treynor-Mazuy model to further adjust for size, value and momentum premia. The augmented Treynor-Mazuy model is given by:

$$
\begin{gathered}
R_{p t}-R_{f}=\alpha_{p}+\beta_{p}\left(R_{m t}-R_{f}\right)+c_{p}\left(R_{m t}-R_{f}\right)^{2}+ \\
s_{p} S M B_{t}+h_{p} H M L_{t}+m_{p} U M D+\varepsilon_{p t}
\end{gathered}
$$

Finally, we have modified the Treynor-Mazuy model to include $S M B, H M L$ and MOM factors in levels as well as their squares. In this way, one could test for the funds' timing ability with respect to these factors as follows: ${ }^{3}$

3. We would like to thank an anonymous referee for this suggestion. 


$$
\begin{gathered}
R_{p t}-R_{f}=a_{p}+\beta_{p}\left(R_{m t}-R_{f}\right)+s_{1 p} S M B_{t}+s_{2 p} S M B_{p}^{2}+ \\
h_{1 p} H M L_{t}+h_{2 p} H M L_{p}^{2}+m_{1 p} U M D_{t}+m_{2 p} U M D_{p}^{2}+\varepsilon_{p t}
\end{gathered}
$$

where $R_{m t}-R_{f}, S M B_{t}$ and $H M L_{t}$ stand for the returns of Fama and French's factor-mimicking portfolios on the market, size and value, respectively, $U M D_{t}$ is the return of Carhart's momentum factor.

\section{Results}

This section presents the empirical results of the study. Table 2 presents the results for the simple risk-adjusted performance measures (Sharpe ratio and Treynor ratio) as well as the average monthly return, the standard deviation of returns and the systematic risk beta coefficient. Overall, funds' betas were very close to 1 and, with the exception of few funds that exhibited negative average returns, most of the funds exhibited Sharpe and Treynor ratios that are comparable to the ones yielded by the S\&P 500 and passive index funds.

Table 3 presents the empirical results using Jensen's alpha as performance measure. Panel A reports results for the full sample period January 2007-March 2013, while Panels B and C report the corresponding results for the subperiods January 2007-December 2009 and January 2010-March 2013. ${ }^{4}$ There is no fund that yielded economically or statistically significant Jensen alpha in the full sample period. To the contrary, there are 8 funds that actually yielded significantly negative alphas. Very similar are the results from the subperiod analysis. In particular, there is only one fund that exhibited a significantly positive Jensen alpha during the crisis period. In the aftermath of the crisis period, when these funds could potentially exploit investors' biases, most of them yielded negative market-adjusted returns, which was found to be even statistically significant for 9 funds. Our results are in broad agreement with Santoni and Kelshiker (2010), who found no evidence of outperformance in terms of Jensen alphas,

4. These results are also in accordance with relevant market timing studies regarding mutual funds (e.g. Elton, Gruber and Blake, 2012) or closed end funds (e.g. Kousenidis and Negakis, 2012) revealing that on average fund managers do not present superior market timing skills. 
TABLE 2. Descriptive statistics and behavioral funds' risk-adjusted performance

\begin{tabular}{|c|c|c|c|c|c|}
\hline Fund & Av. monthly return & St. Dev. & beta & Sharpe ratio & Treynor ratio \\
\hline Av. Fund & $0.33 \%$ & $5.57 \%$ & 1.067 & 0.044 & $0.23 \%$ \\
\hline 1 & $0.47 \%$ & $5.82 \%$ & 1.088 & 0.066 & $0.36 \%$ \\
\hline 2 & $0.80 \%$ & $7.54 \%$ & 1.351 & 0.094 & $0.53 \%$ \\
\hline 3 & $0.40 \%$ & $6.73 \%$ & 1.144 & 0.047 & $0.28 \%$ \\
\hline 4 & $0.16 \%$ & $5.24 \%$ & 0.962 & 0.013 & $0.07 \%$ \\
\hline 5 & $-0.10 \%$ & $5.80 \%$ & 1.082 & -0.033 & $-0.18 \%$ \\
\hline 6 & $0.50 \%$ & $6.08 \%$ & 1.125 & 0.067 & $0.36 \%$ \\
\hline 7 & $-0.13 \%$ & $6.56 \%$ & 1.217 & -0.034 & $-0.18 \%$ \\
\hline 8 & $0.14 \%$ & $5.93 \%$ & 1.117 & 0.009 & $0.05 \%$ \\
\hline 9 & $0.37 \%$ & $6.73 \%$ & 1.144 & 0.043 & $0.25 \%$ \\
\hline 10 & $0.30 \%$ & $5.17 \%$ & 0.985 & 0.041 & $0.22 \%$ \\
\hline 11 & $0.22 \%$ & $5.36 \%$ & 1.017 & 0.026 & $0.13 \%$ \\
\hline 12 & $0.30 \%$ & $5.49 \%$ & 1.036 & 0.038 & $0.20 \%$ \\
\hline 13 & $0.49 \%$ & $5.23 \%$ & 0.981 & 0.076 & $0.41 \%$ \\
\hline 14 & $0.08 \%$ & $5.46 \%$ & 1.001 & -0.001 & $0.00 \%$ \\
\hline 15 & $0.01 \%$ & $5.63 \%$ & 1.034 & -0.013 & $-0.07 \%$ \\
\hline 16 & $0.32 \%$ & $5.78 \%$ & 0.964 & 0.040 & $0.24 \%$ \\
\hline 17 & $0.42 \%$ & $5.36 \%$ & 0.818 & 0.061 & $0.40 \%$ \\
\hline 18 & $-0.86 \%$ & $5.68 \%$ & 0.919 & -0.166 & $-1.03 \%$ \\
\hline 19 & $-0.12 \%$ & $5.65 \%$ & 0.925 & -0.036 & $-0.22 \%$ \\
\hline 20 & $0.07 \%$ & $7.21 \%$ & 1.237 & -0.002 & $-0.01 \%$ \\
\hline 21 & $0.56 \%$ & $6.33 \%$ & 1.120 & 0.074 & $0.42 \%$ \\
\hline 22 & $0.28 \%$ & $6.06 \%$ & 1.102 & 0.032 & $0.17 \%$ \\
\hline SPY & $0.27 \%$ & $5.04 \%$ & 0.967 & 0.035 & $0.18 \%$ \\
\hline VFINX & $0.27 \%$ & $5.05 \%$ & 0.971 & 0.036 & $0.18 \%$ \\
\hline FUSEX & $0.27 \%$ & $5.03 \%$ & 0.966 & 0.037 & $0.19 \%$ \\
\hline S\&P 500 & $0.27 \%$ & $5.08 \%$ & 0.977 & 0.035 & $0.18 \%$ \\
\hline Market & $0.50 \%$ & $5.18 \%$ & 1.000 & 0.079 & $0.41 \%$ \\
\hline
\end{tabular}

Note: This table reports the average monthly return, the standard deviation of returns ( $\mathrm{St}$. Dev.), the coefficient of systematic risk (beta), Sharpe ratio and Treynor ratio for the average behavioral fund (average return of the 22 behavioral funds), the individual twenty two behavioral funds, the three passive funds, the S\&P 500 index and the US market return as proxied by the US market returns retrieved from the Kenneth French's online data library. Monthly data for the period from January 2007 to March 2013. 


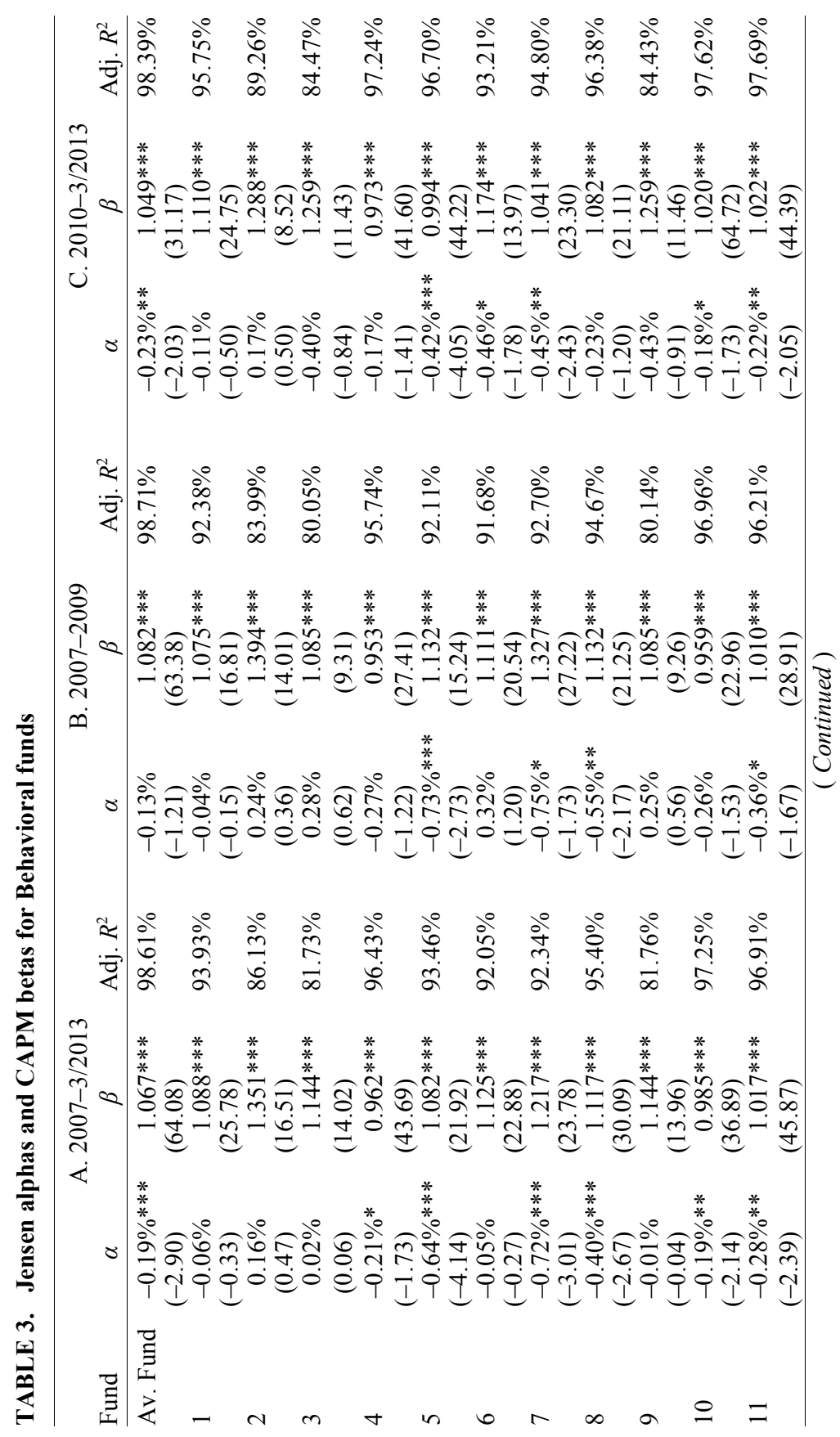




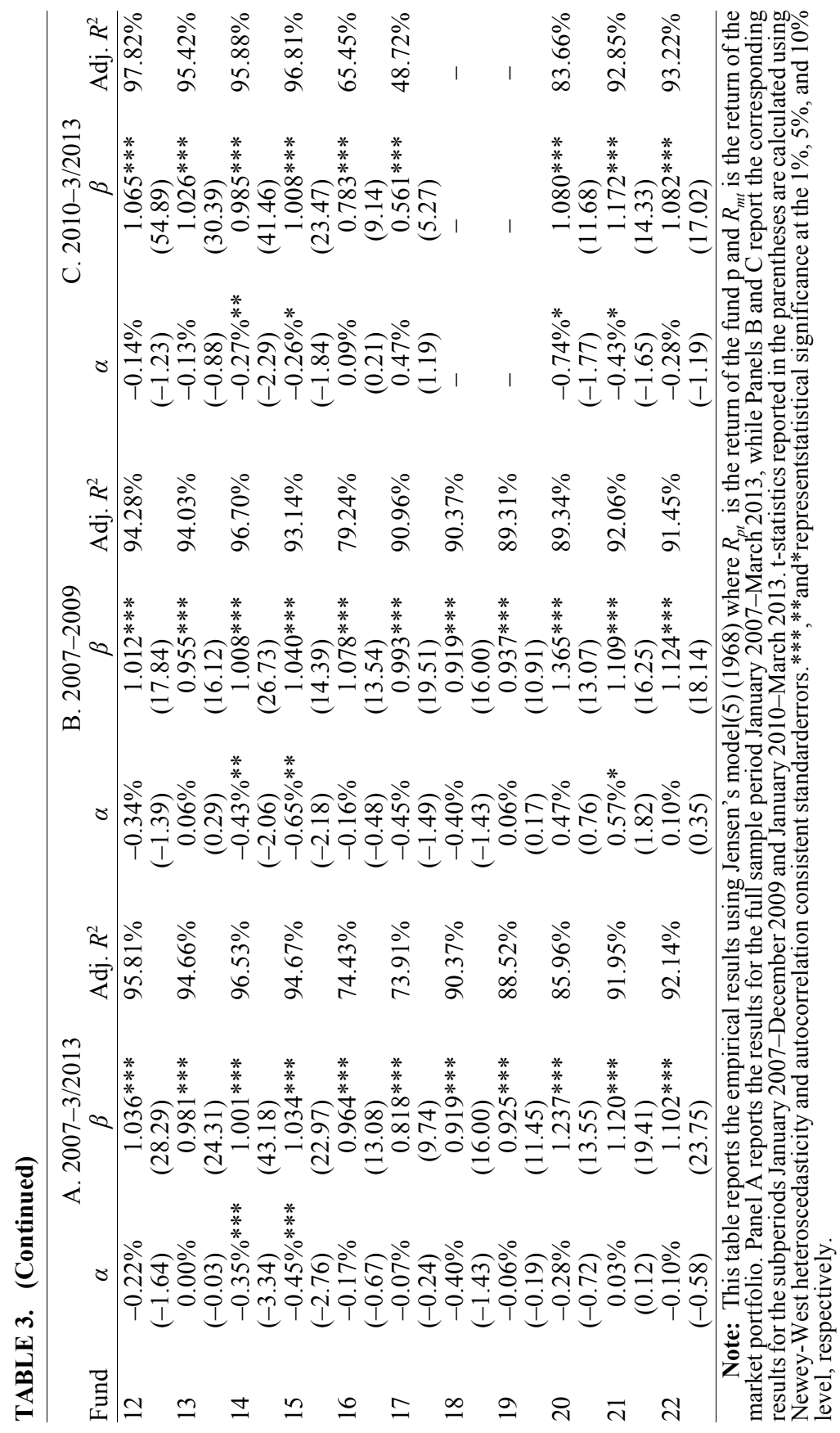


TABLE 4. Jensen alphas and CAPM betas for Behavioral funds relative to benchmark index

\begin{tabular}{|c|c|c|c|}
\hline \multicolumn{4}{|c|}{$2007-3 / 2013$} \\
\hline Fund & $\alpha$ & $\beta$ & Adj. $R^{2}$ \\
\hline \multirow[t]{2}{*}{1} & $-0.02 \%$ & $0.948 * * *$ & $97.70 \%$ \\
\hline & $(-0.17)$ & $(35.30)$ & \\
\hline \multirow[t]{2}{*}{2} & $0.49 \% *$ & $1.102 * * *$ & $93.12 \%$ \\
\hline & $(1.87)$ & $(20.82)$ & \\
\hline \multirow[t]{2}{*}{3} & $-0.11 \%$ & $0.972 * * *$ & $91.15 \%$ \\
\hline & $(-0.49)$ & (23.96) & \\
\hline \multirow[t]{2}{*}{4} & $0.19 \%$ & $0.913^{* * *}$ & $93.93 \%$ \\
\hline & $(1.15)$ & $(20.73)$ & \\
\hline \multirow[t]{2}{*}{5} & $-0.39 \%$ *** & $1.109^{* * *}$ & $94.31 \%$ \\
\hline & $(-3.01)$ & $(23.90)$ & \\
\hline \multirow[t]{2}{*}{6} & $0.24 \%$ & $0.882 * * *$ & $91.83 \%$ \\
\hline & $(1.21)$ & $(26.86)$ & \\
\hline \multirow[t]{2}{*}{7} & $-0.45 \% *$ & $1.241 * * *$ & $92.11 \%$ \\
\hline & $(-1.81)$ & $(25.49)$ & \\
\hline \multirow[t]{2}{*}{8} & $0.02 \%$ & $1.082 * * *$ & $97.51 \%$ \\
\hline & $(0.17)$ & $(50.46)$ & \\
\hline \multirow[t]{2}{*}{9} & $-0.14 \%$ & $0.972 * * *$ & $91.20 \%$ \\
\hline & $(-0.62)$ & $(24.04)$ & \\
\hline \multirow[t]{2}{*}{10} & $0.00 \%$ & $0.986^{* * *}$ & $97.36 \%$ \\
\hline & $(0.01)$ & $(36.11)$ & \\
\hline \multirow[t]{2}{*}{11} & $0.10 \%$ & $0.980^{* * *}$ & $98.01 \%$ \\
\hline & $(1.61)$ & $(41.20)$ & \\
\hline \multirow[t]{2}{*}{12} & $-0.02 \%$ & $1.020^{* * *}$ & $95.74 \%$ \\
\hline & $(-0.16)$ & $(28.05)$ & \\
\hline \multirow[t]{2}{*}{13} & $0.00 \%$ & $1.009^{* * *}$ & $97.98 \%$ \\
\hline & $(0.05)$ & (41.95) & \\
\hline \multirow[t]{2}{*}{14} & $-0.12 \%$ & $1.027 * * *$ & $97.22 \%$ \\
\hline & $(-1.27)$ & $(50.77)$ & \\
\hline \multirow[t]{2}{*}{15} & $-0.05 \%$ & $1.008^{* * *}$ & $98.14 \%$ \\
\hline & $(-0.75)$ & $(57.30)$ & \\
\hline \multirow[t]{2}{*}{16} & $-0.01 \%$ & $0.954 * * *$ & $75.01 \%$ \\
\hline & $(-0.03)$ & $(13.46)$ & \\
\hline
\end{tabular}


TABLE 4. (Continued)

\begin{tabular}{|c|c|c|c|}
\hline \multicolumn{4}{|c|}{$2007-3 / 2013$} \\
\hline Fund & $\alpha$ & $\beta$ & Adj. $R^{2}$ \\
\hline \multirow[t]{2}{*}{17} & $0.07 \%$ & $0.809^{* * *}$ & $74.47 \%$ \\
\hline & $(0.26)$ & $(9.91)$ & \\
\hline \multirow[t]{2}{*}{18} & $0.05 \%$ & $0.873^{* * *}$ & $92.79 \%$ \\
\hline & $(0.23)$ & $(31.92)$ & \\
\hline \multirow[t]{2}{*}{19} & $-0.13 \%$ & $0.969^{* * *}$ & $95.19 \%$ \\
\hline & $(-0.58)$ & $(22.72)$ & \\
\hline \multirow[t]{2}{*}{20} & $0.23 \%$ & $1.179^{* * *}$ & $84.48 \%$ \\
\hline & $(0.50)$ & (12.96) & \\
\hline \multirow[t]{2}{*}{21} & $0.22 \%$ & $0.887 * * *$ & $92.66 \%$ \\
\hline & $(1.08)$ & $(26.55)$ & \\
\hline \multirow[t]{2}{*}{22} & $-0.05 \%$ & $0.956 * * *$ & $95.08 \%$ \\
\hline & $(-0.43)$ & $(38.73)$ & \\
\hline
\end{tabular}

Note: This table reports the empirical results using Jensen's model (1968) relative to each individual fund benchmark index:

$$
R_{p t}-R_{f}=\alpha_{p}+\beta_{p}\left(R_{m t}-R_{f}\right)+\varepsilon_{p t},
$$

where $R_{p t}$ is the return of the fund $p$ and $R_{m t}$ is the return of the benchmark index, for the period January 2007 to March 2013. t-statistics reported in the parentheses are calculated using Newey-West heteroscedasticity and autocorrelation consistent standard errors. ***,** and $*$ represent statistical significance at the $1 \%, 5 \%$, and $10 \%$ level, respectively.

but contrasts the findings of Wright et al. (2006). This is due to the fact that the latter study examined a much earlier sample period (mostly before 2004), when behavioral funds were much smaller in size and could potentially implement their strategies in a profitable manner.

Table 4 reports the corresponding full sample results when we use the benchmark index that each fund self-reports rather than the market index. Again, there is no evidence of significant outperformance, but now there are fewer negative alpha estimates and only 2 of them are statistically significant. In sum, using self-reported benchmark indices yields a more favourable picture for funds' performance, but still there is no evidence of outperformance.

Following the approach of Wright et al. (2006), table 5 reports funds' alphas estimated from the Carhart model in (4), i.e. after adjusting for market, size, value and momentum premia. As in table 3, we report results for the full sample period in Panel A and the corresponding subperiod results in Panels B and C, respectively. Carhart alphas yield results that are very similar to the ones using Jensenalphas.For the majority of funds we report negative risk-adjusted 


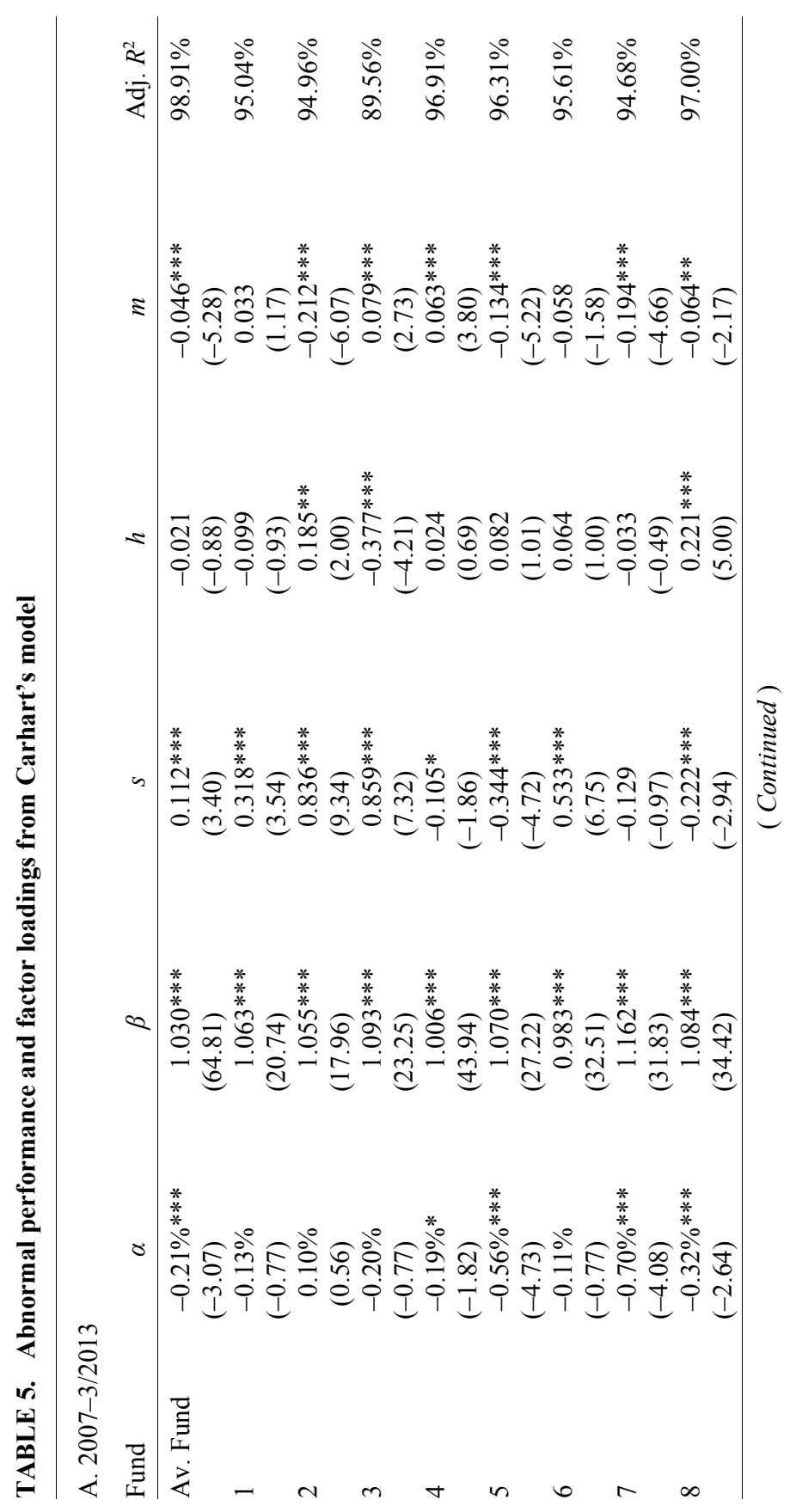




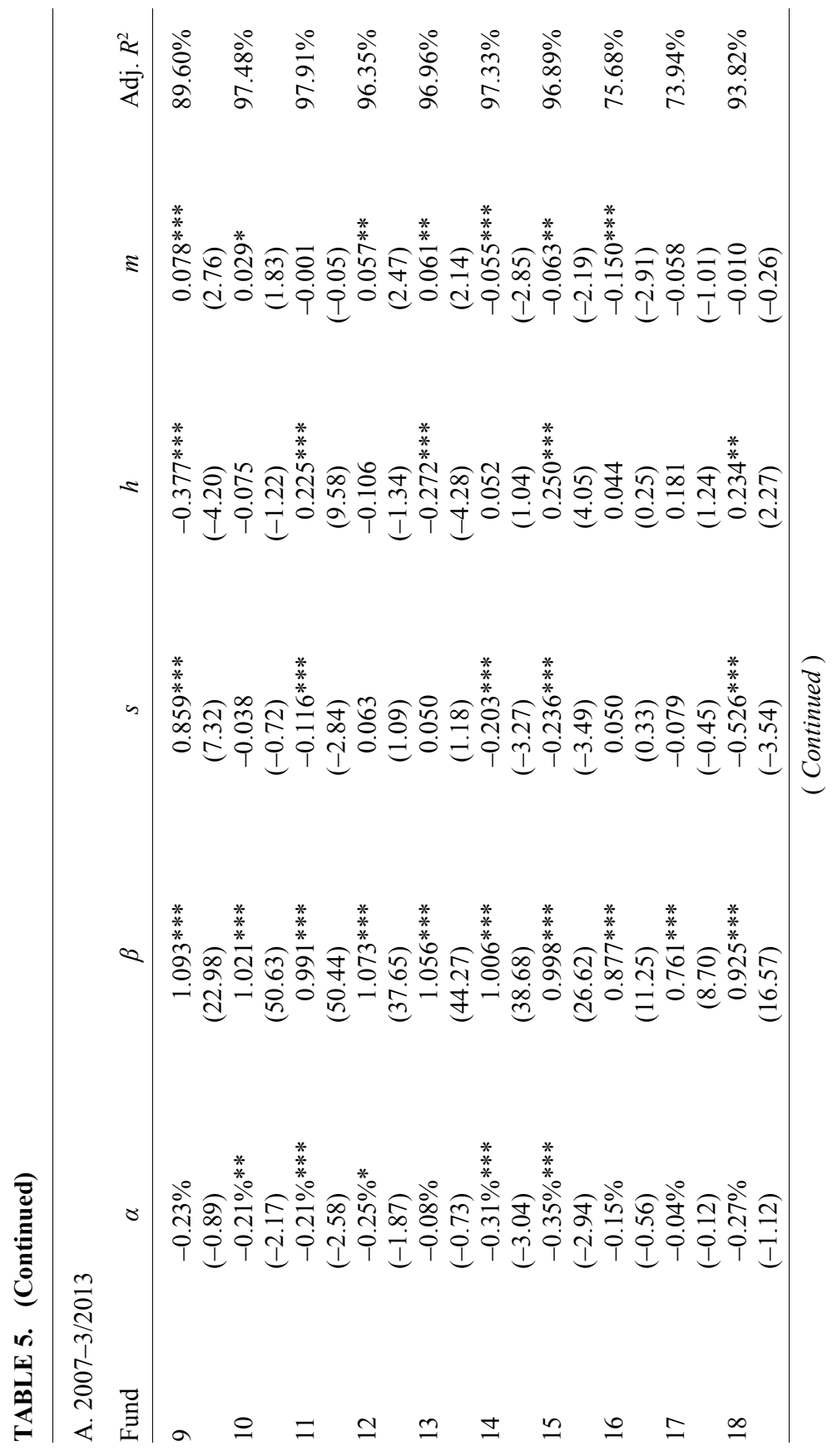




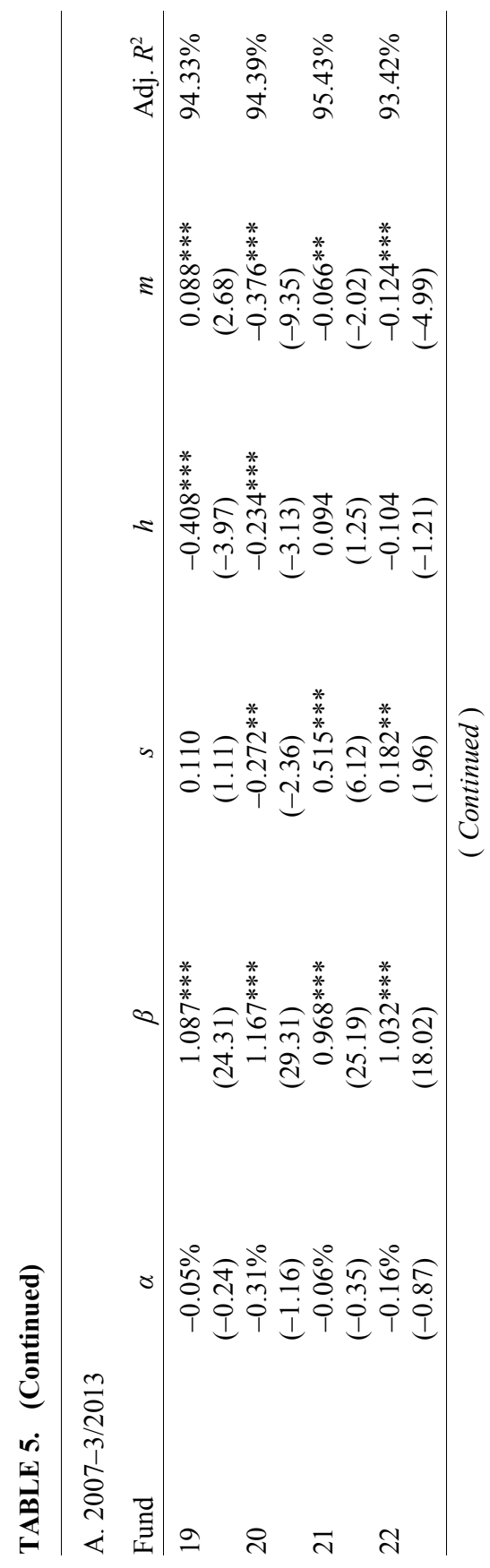




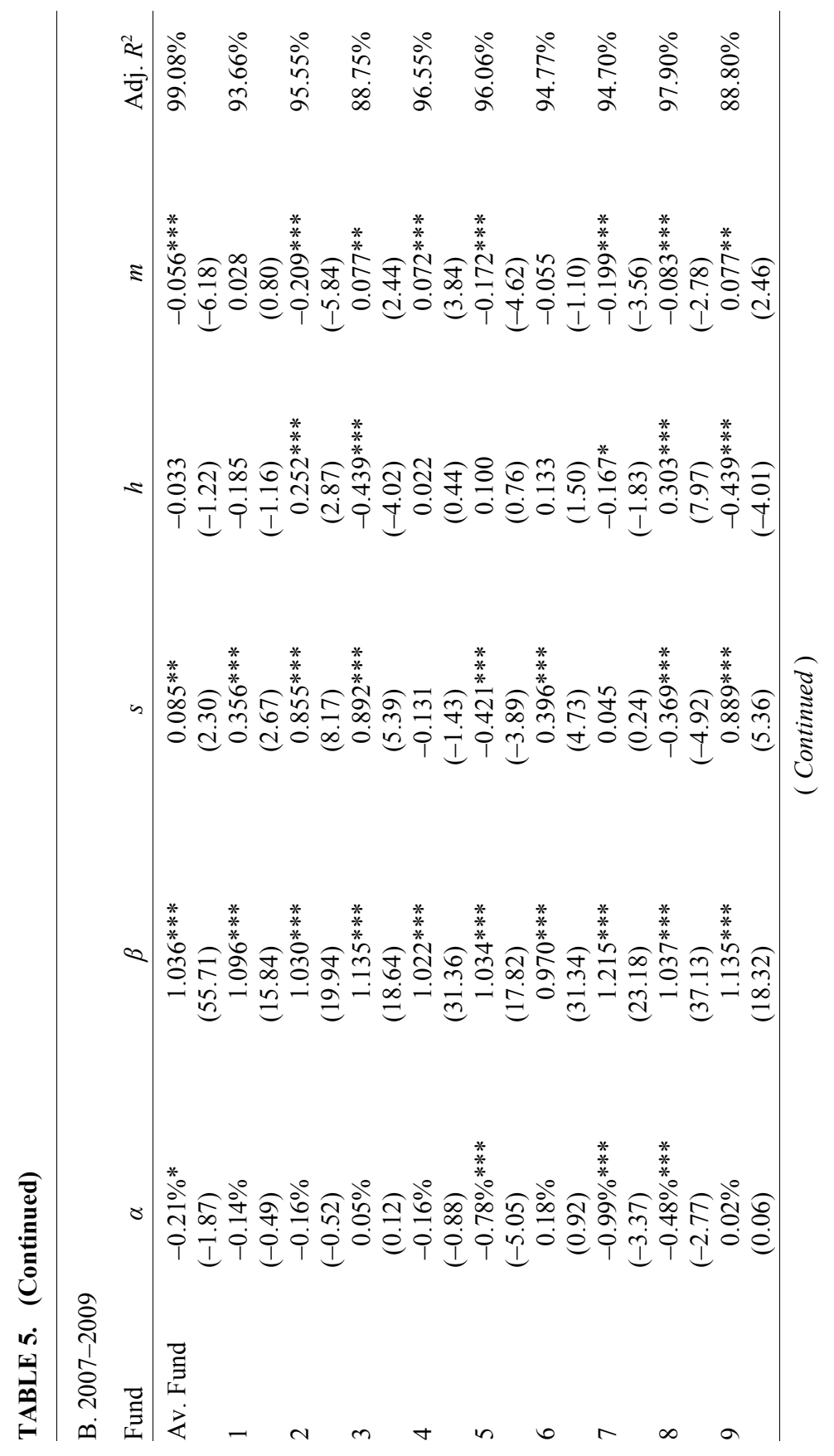




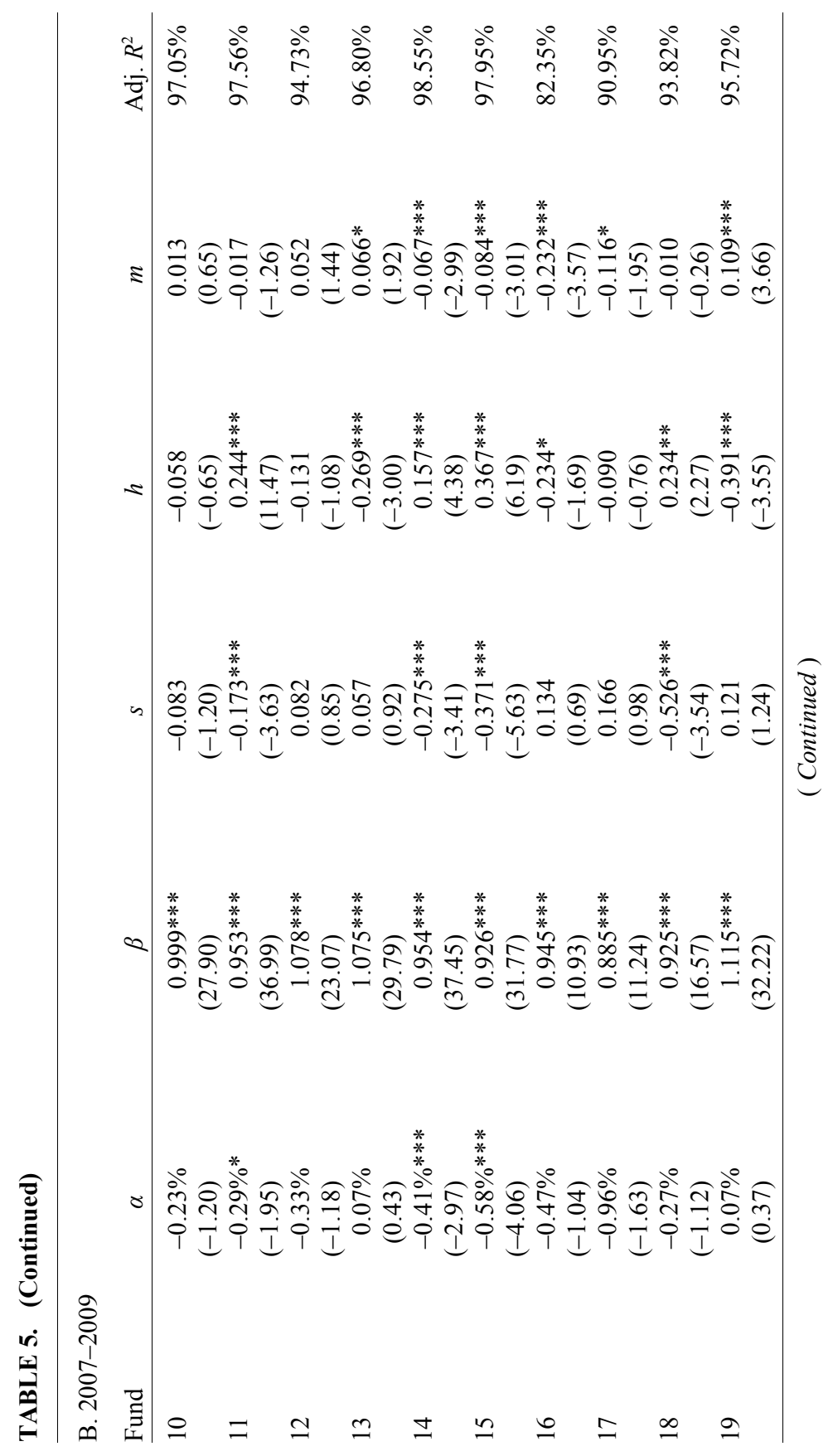




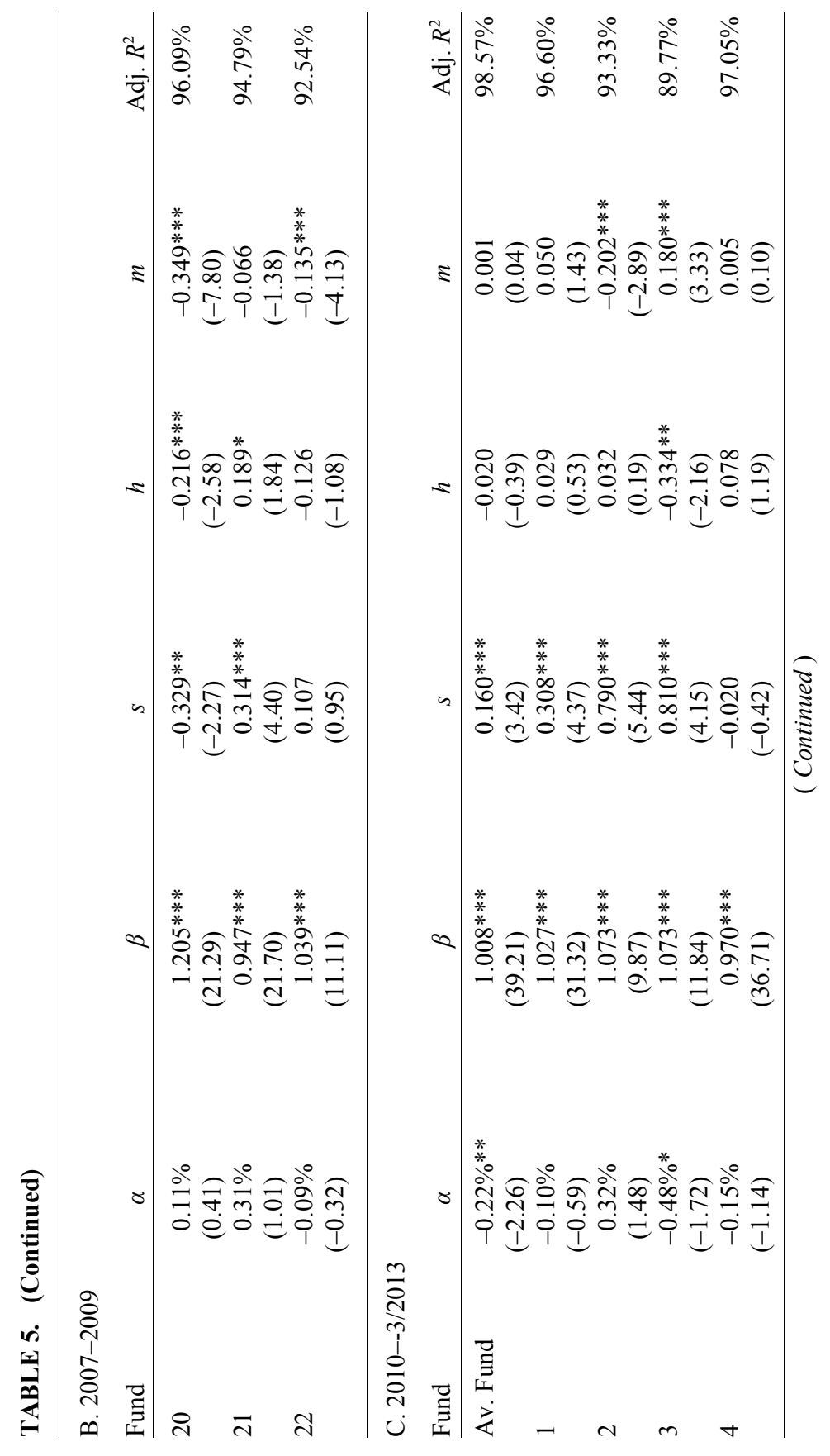




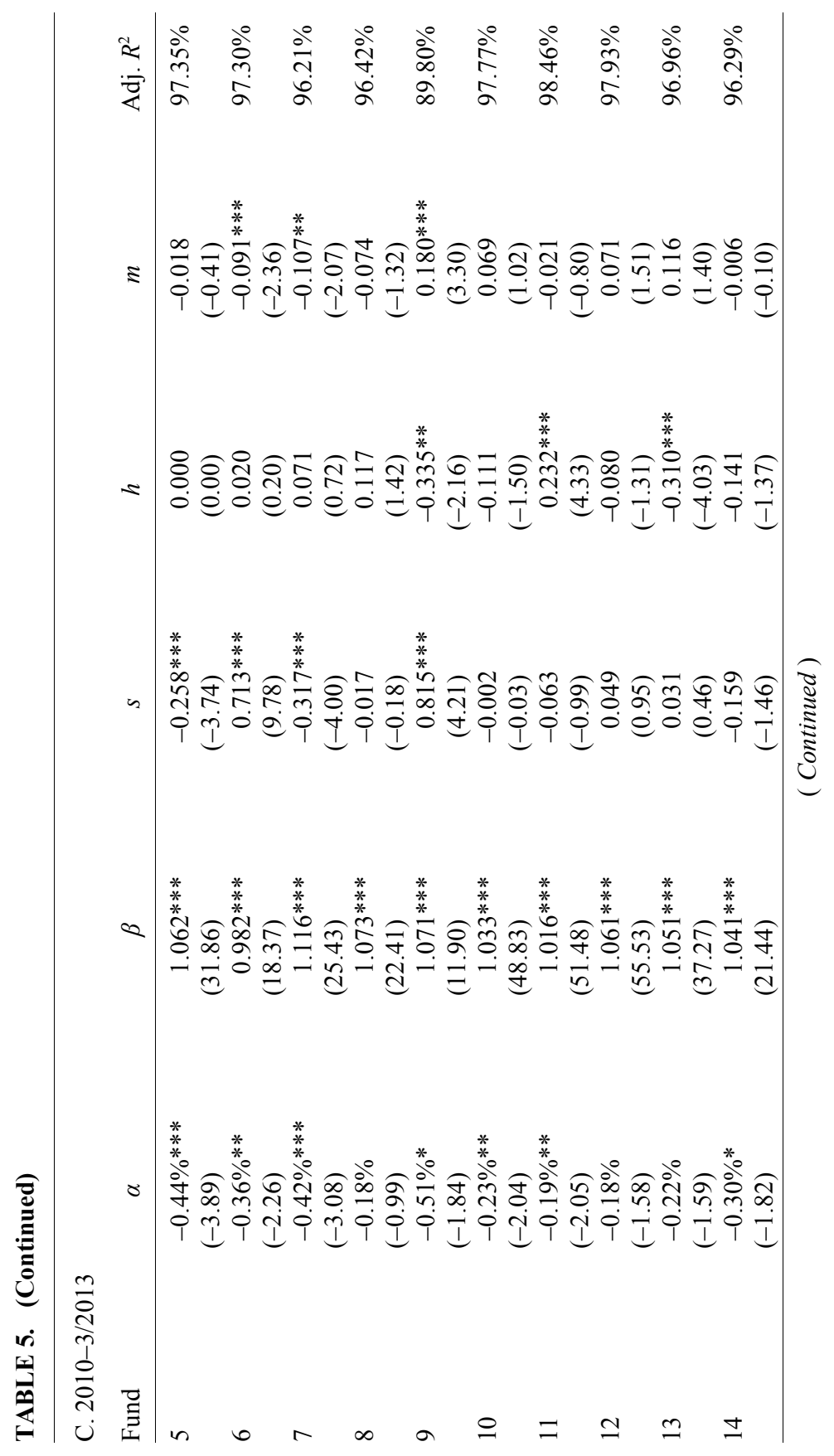




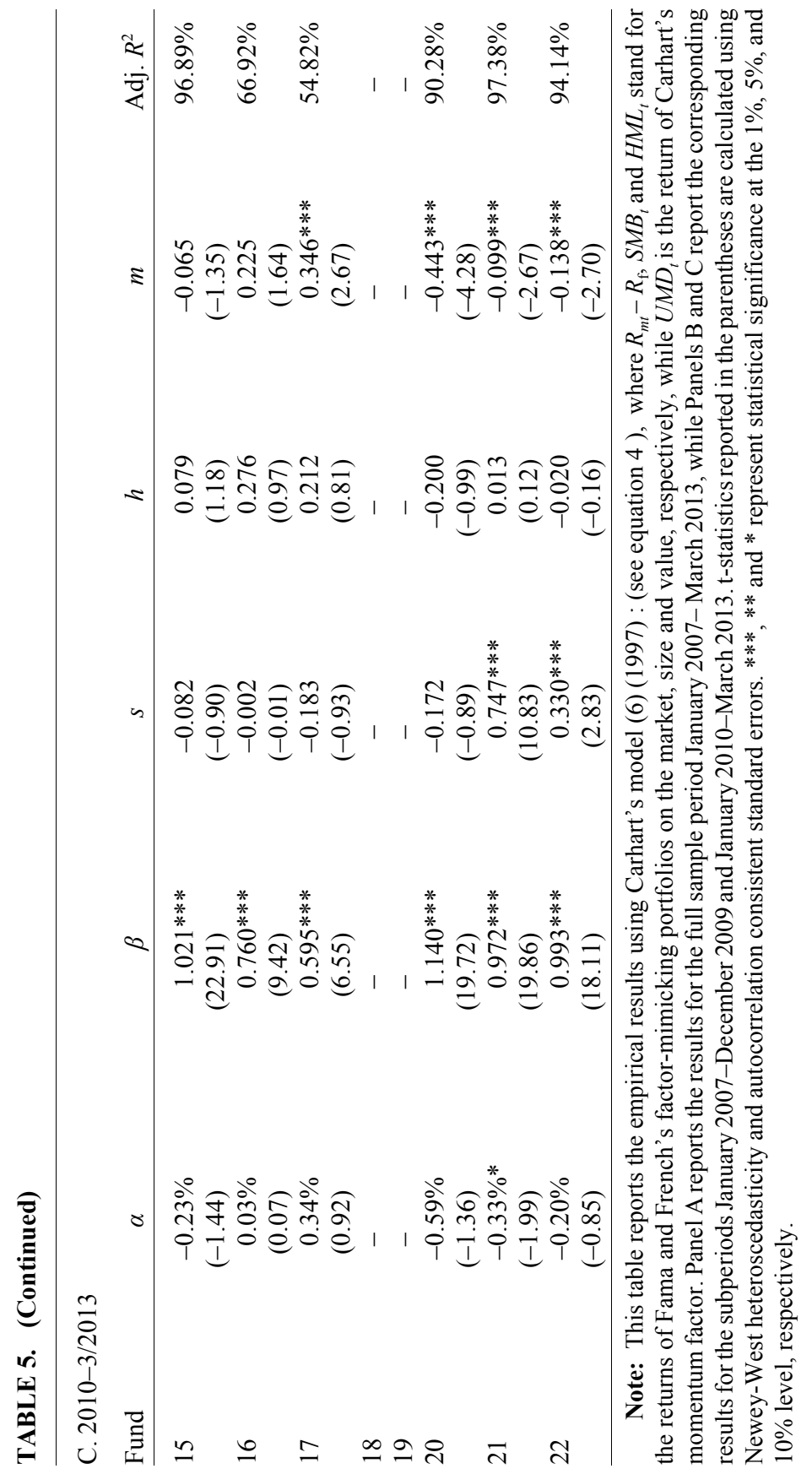




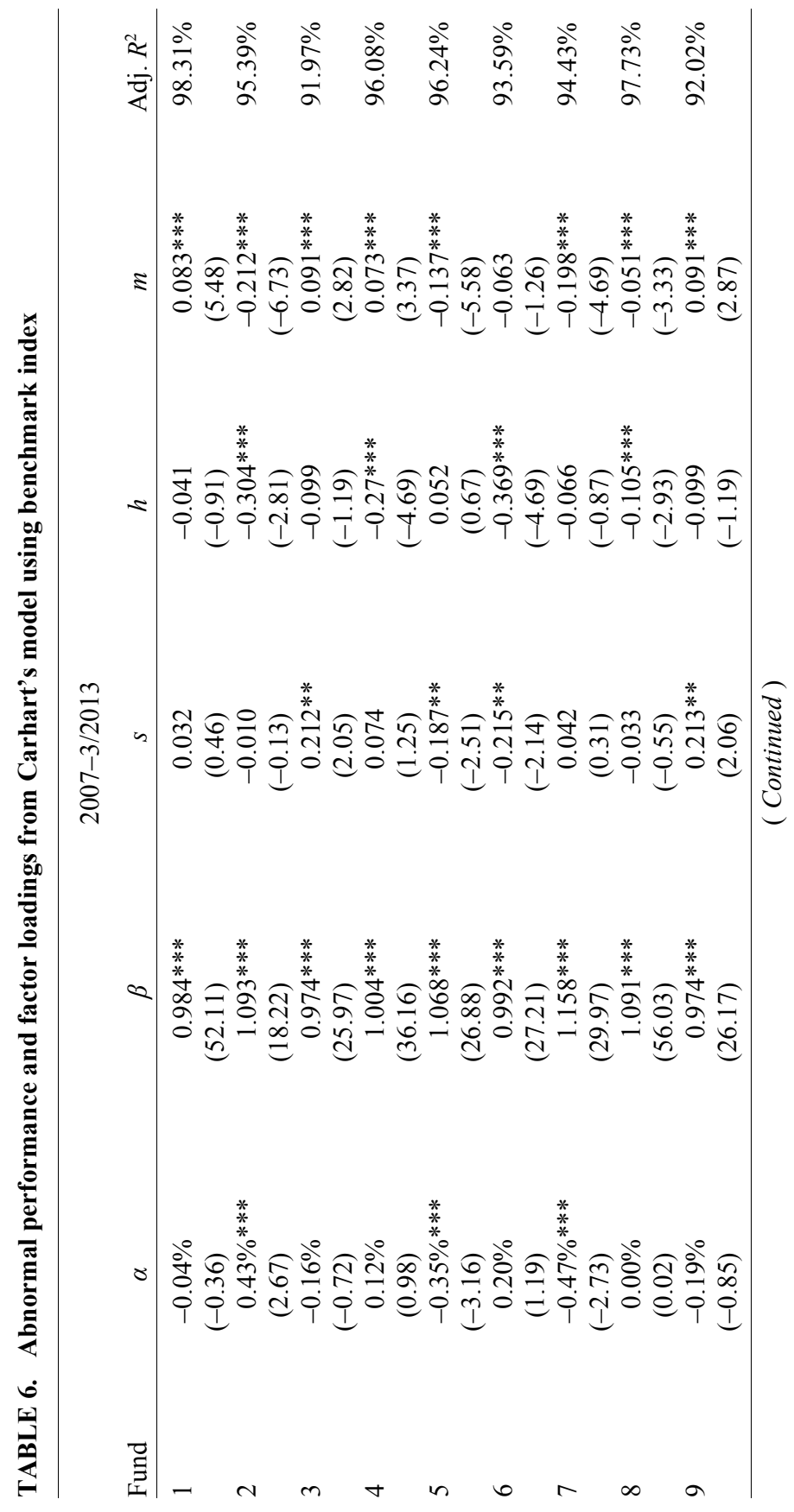




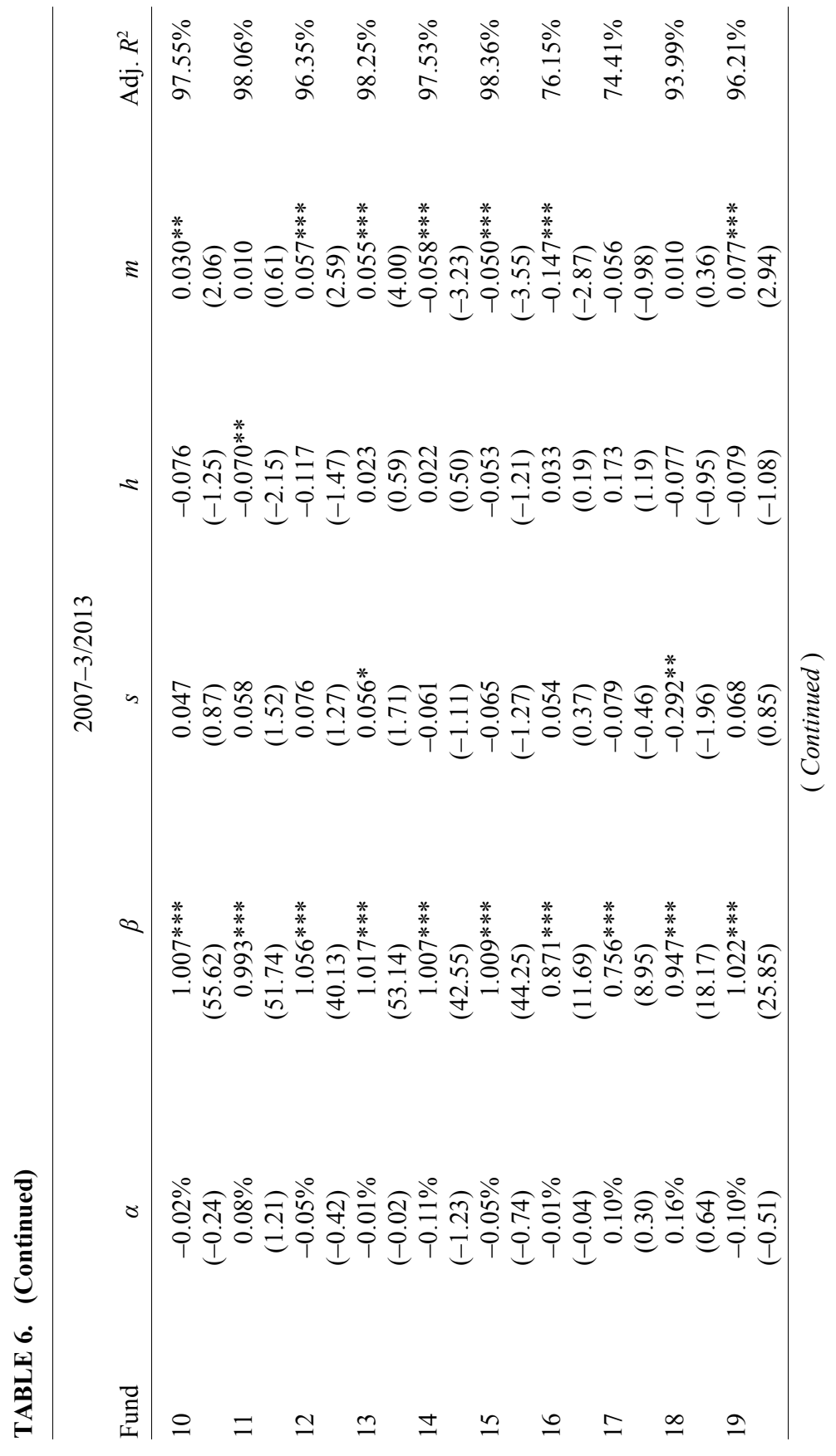




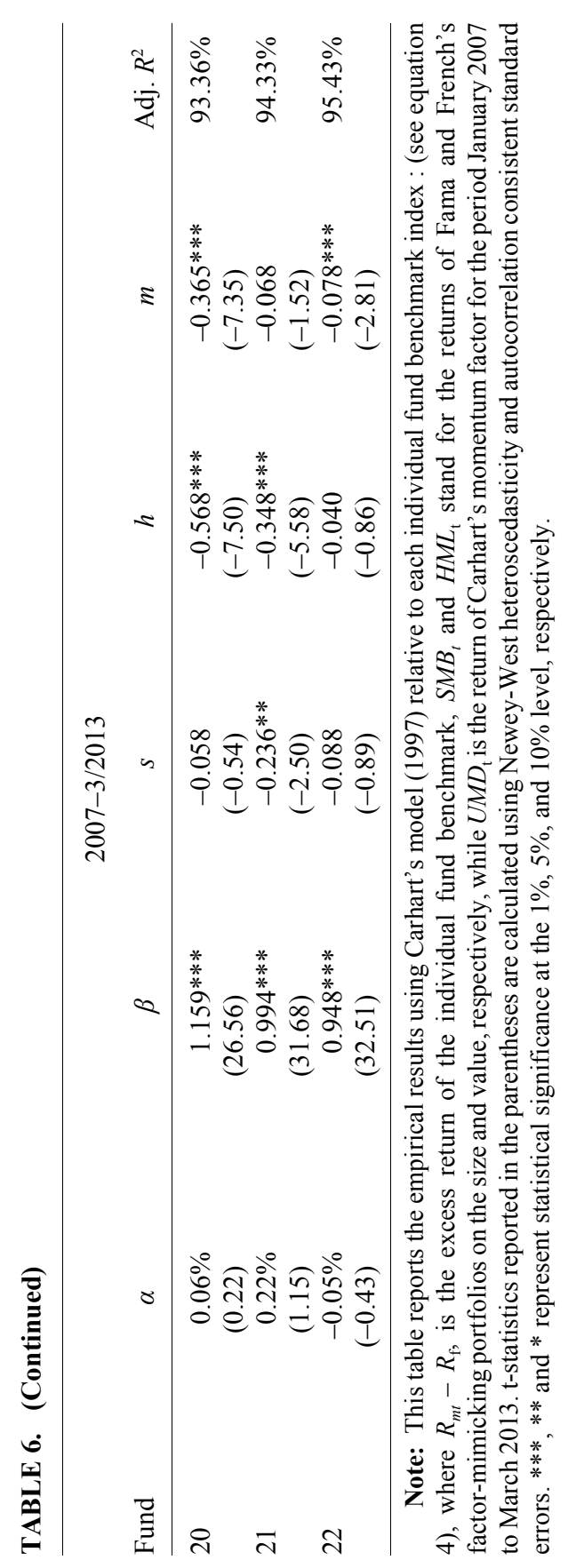


performance and for a large number of them, this evidence is economically and statistically significant. These findings hold in the full sample period as well as in the subperiods considered. It should be noted that there is no fund, regardless of the period examined, that yields a significant positive Carhart alpha. These results are qualitatively similar to the evidence provided by Wright et al. (2006), who also find no significant outperformance using the 4-factor Carhart model. They argue that Carhart alphas are reduced relative to Jensen alphas because of funds' positive loading to value $(H M L)$ factor. Contrary to their results, we do not find any systematic evidence that behavioral funds mimic value strategies. Moreover, while we find significant loadings on the size and momentum factors, these are positive for some funds and negative for others, and hence it cannot be argued that these funds systematically implemented size or momentum strategies. Finally, when we use as benchmark index the one that funds self-reported, this significant underperformance disappears and Carhart alphas reported in table 6 are mostly insignificant.

We further augment Carhart's model with an additional explanatory variable in order to estimate managers' ability to capture market sentiment, as it is proxied by the CBOE implied volatility index VIX (see Baker and Wurgler, 2006). According to the results reported in Panel A of table 7 none of the funds has a statistically significant sentiment coefficient $(v)$ in the full sample period. Only during the recovery period from 2010 to March 2013 (Panel C) do we identify three funds with positive and two funds with negative and statistically significant $V I X$ coefficients.

The next step is to estimate the Treynor-Mazuy model to examine whether these funds had significant market timing ability. Results are reported in table 8 for the full sample period (Panel A) as well as the two subperiods we examine (Panels B and C, respectively). We find no fund with a positive stock picking ability, while 6 funds have negative and statistically significant alphas in the full sample period. Moreover, none of the funds has a superior market timing skill, while four funds exhibited negative market timing ability. ${ }^{5}$ Negative market timing can have devastating consequences for the funds' shareholders, particularly during prolonged bear markets. The subperiod results are similar, with the exception that there were some funds that had significant positive timing ability during the crisis. During the post-crisis period, there was

5. We would like to thank an anonymous referee for this suggestion. 


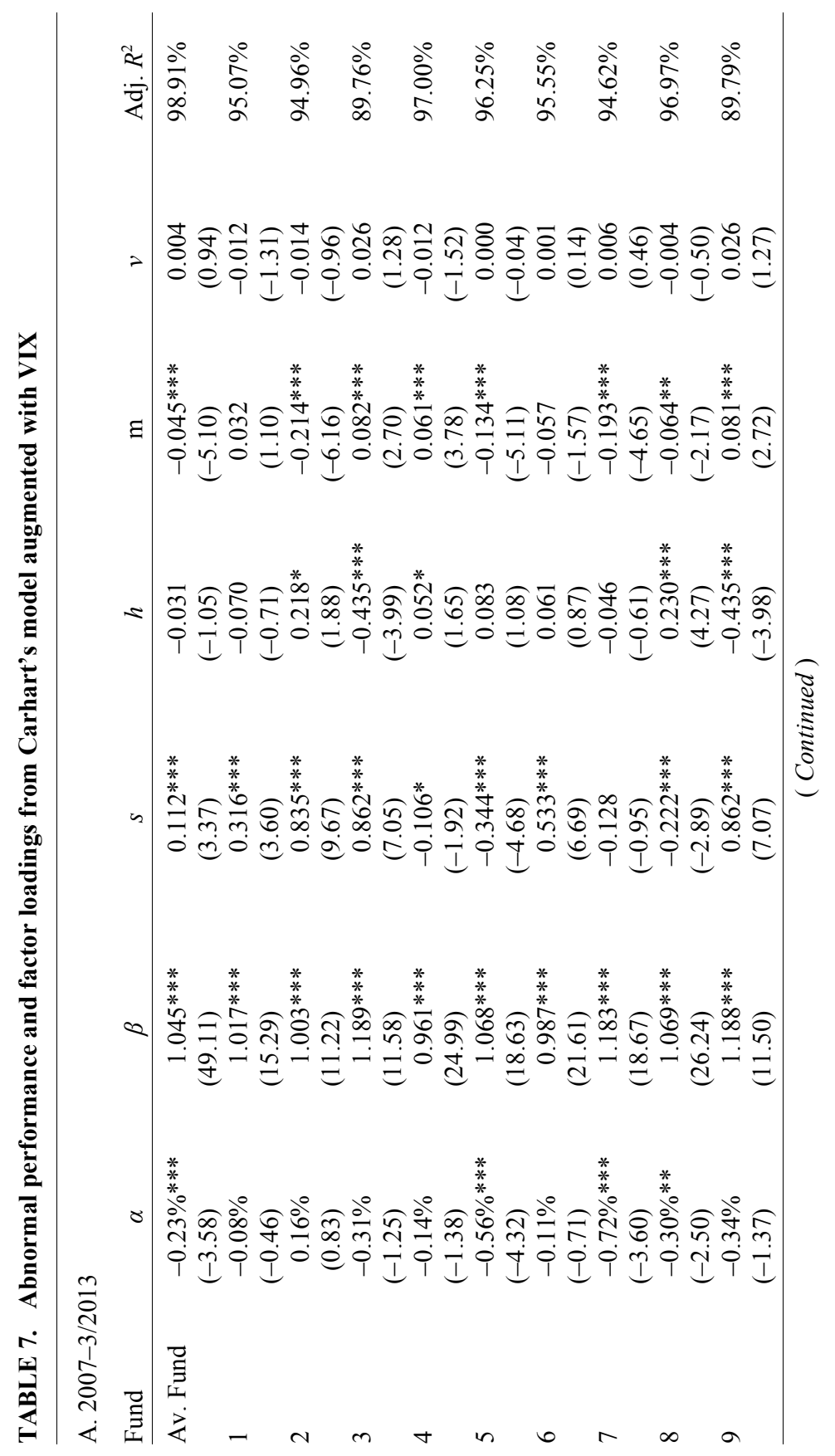




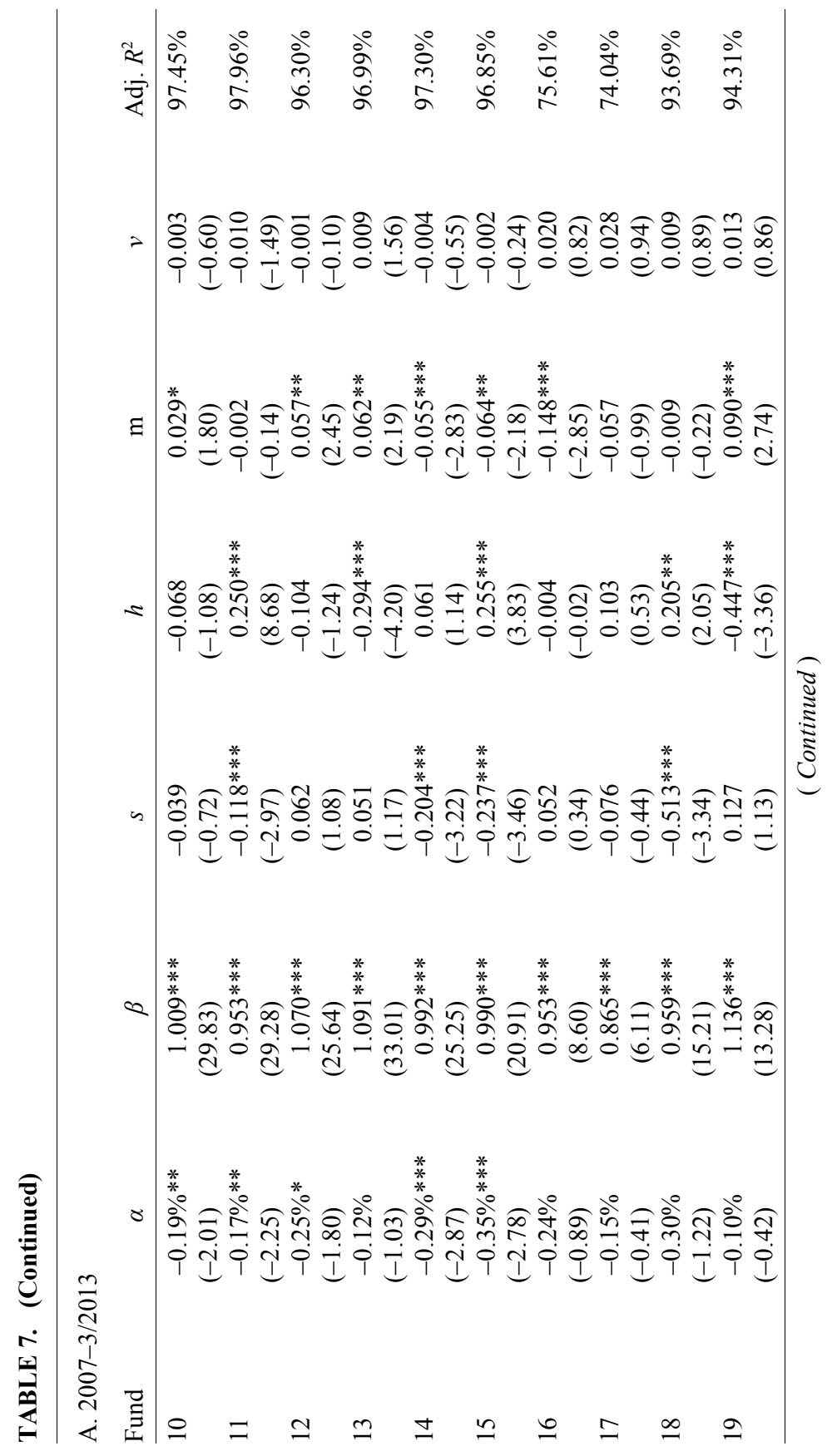




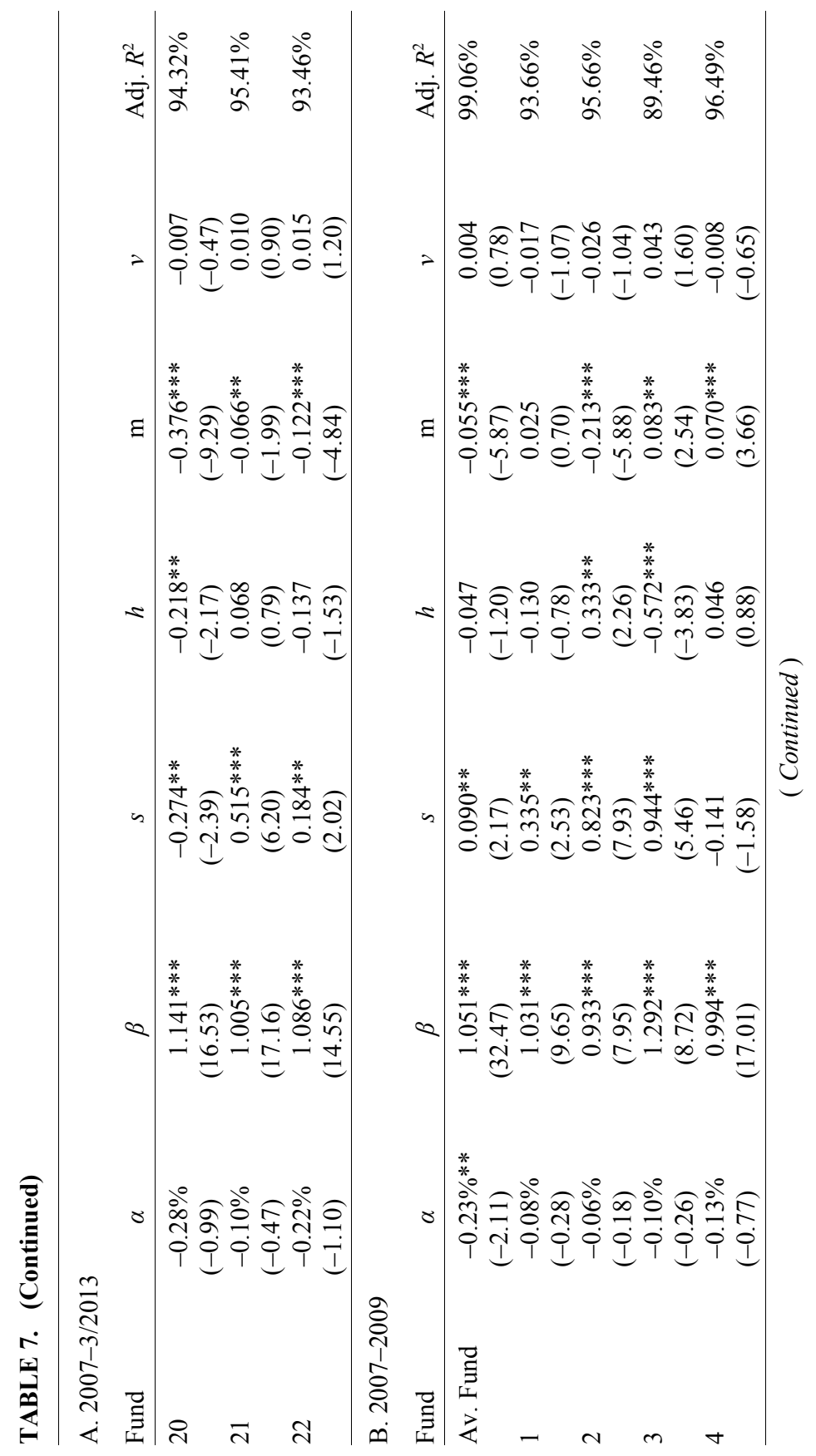




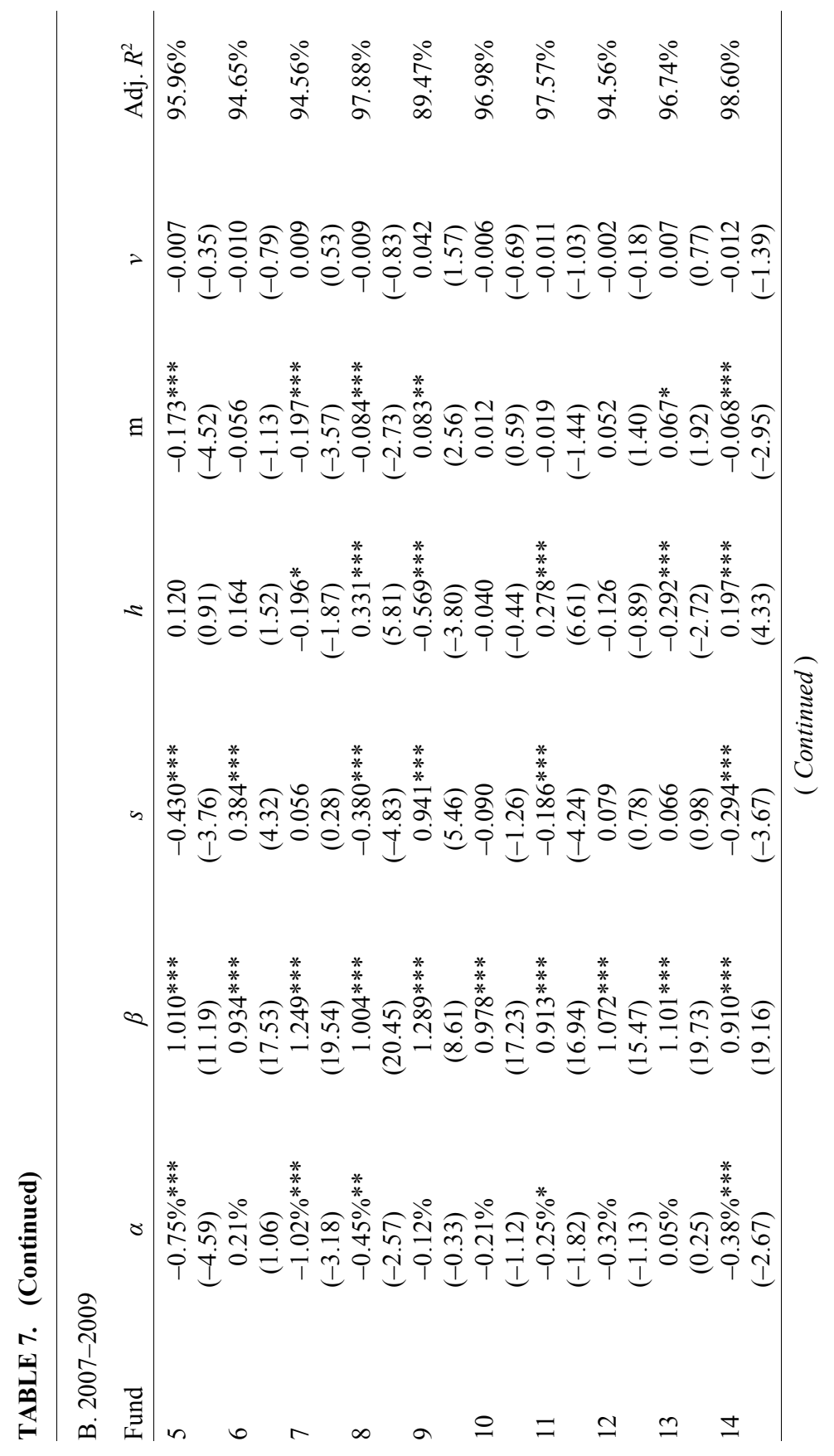




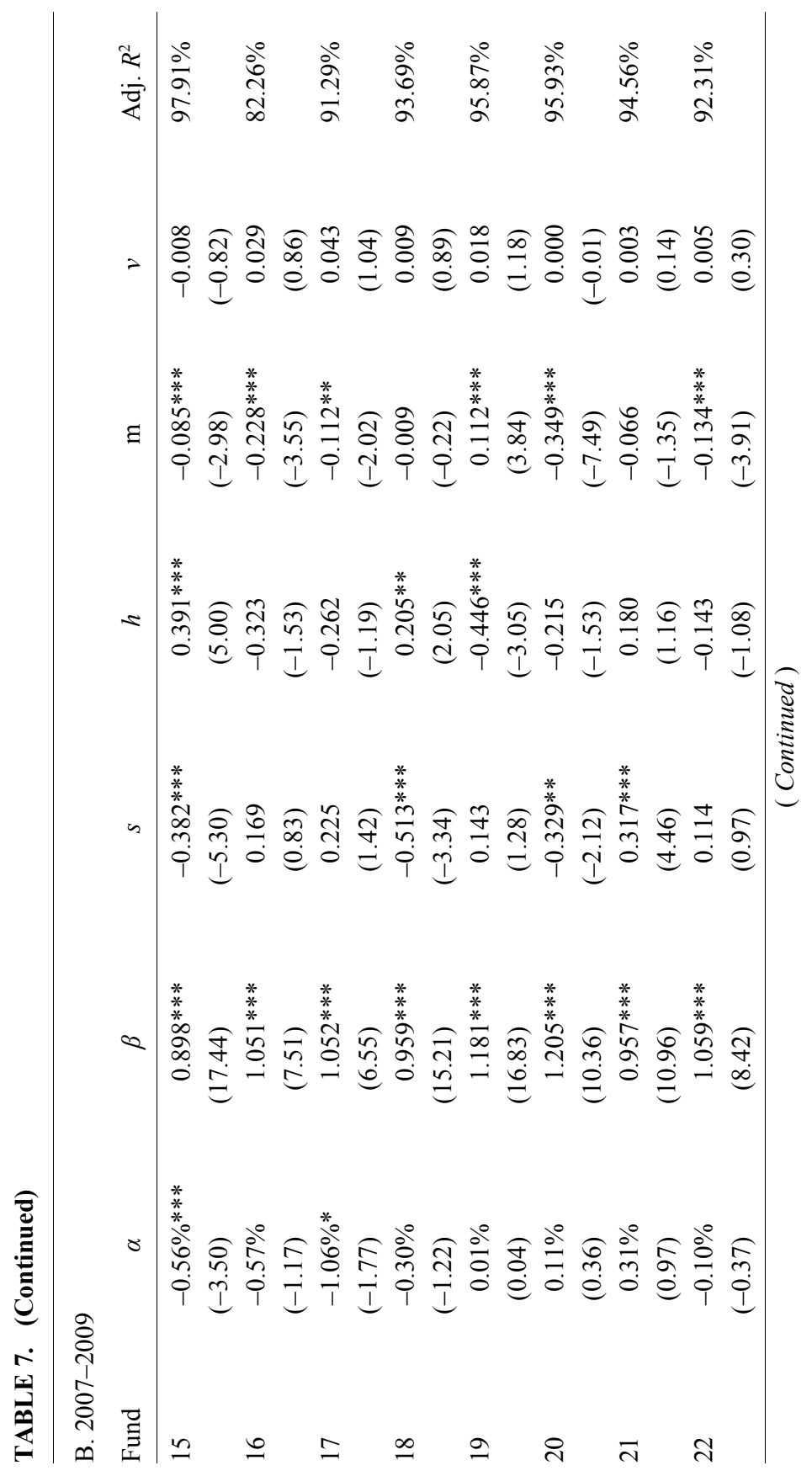




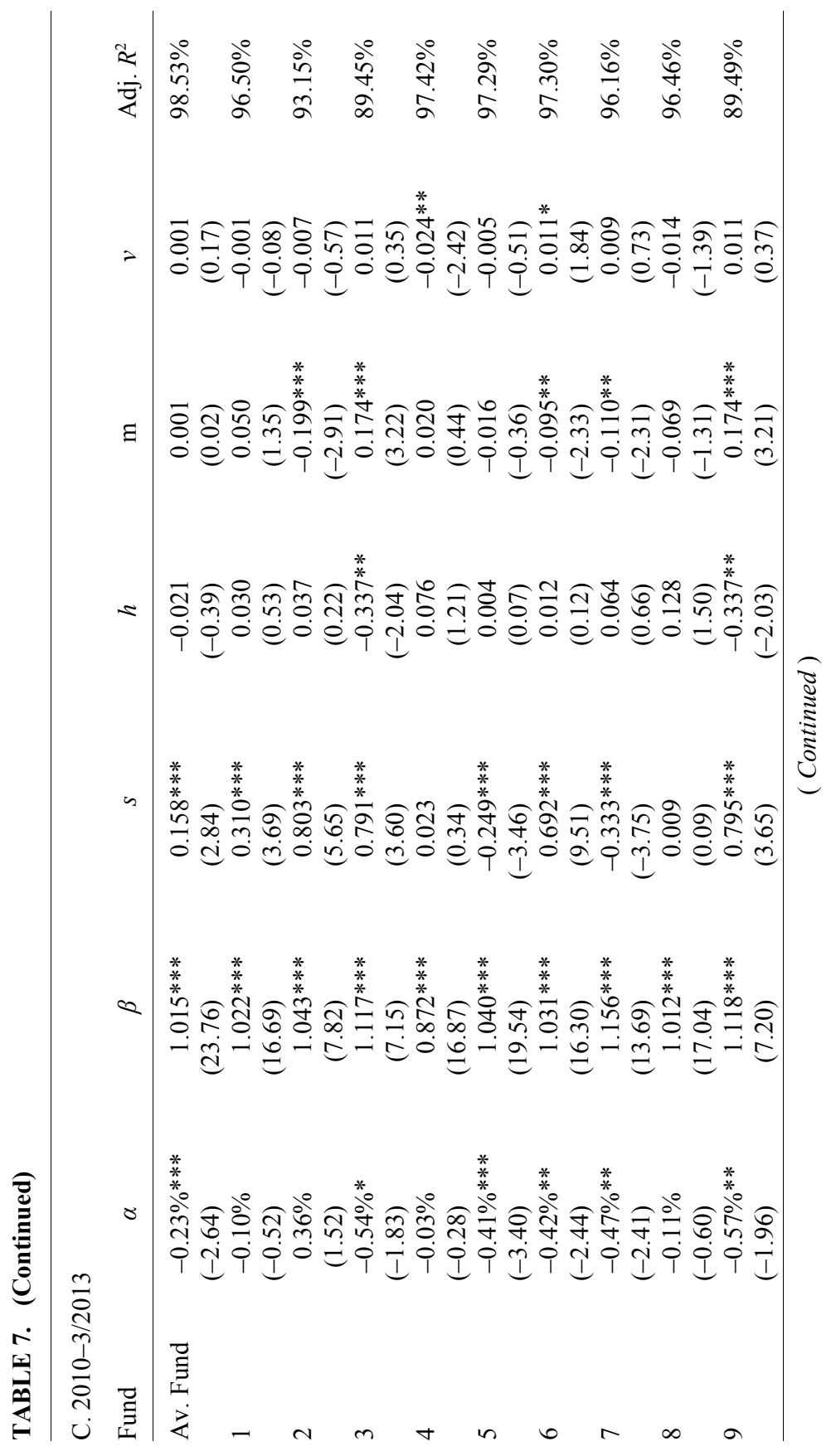




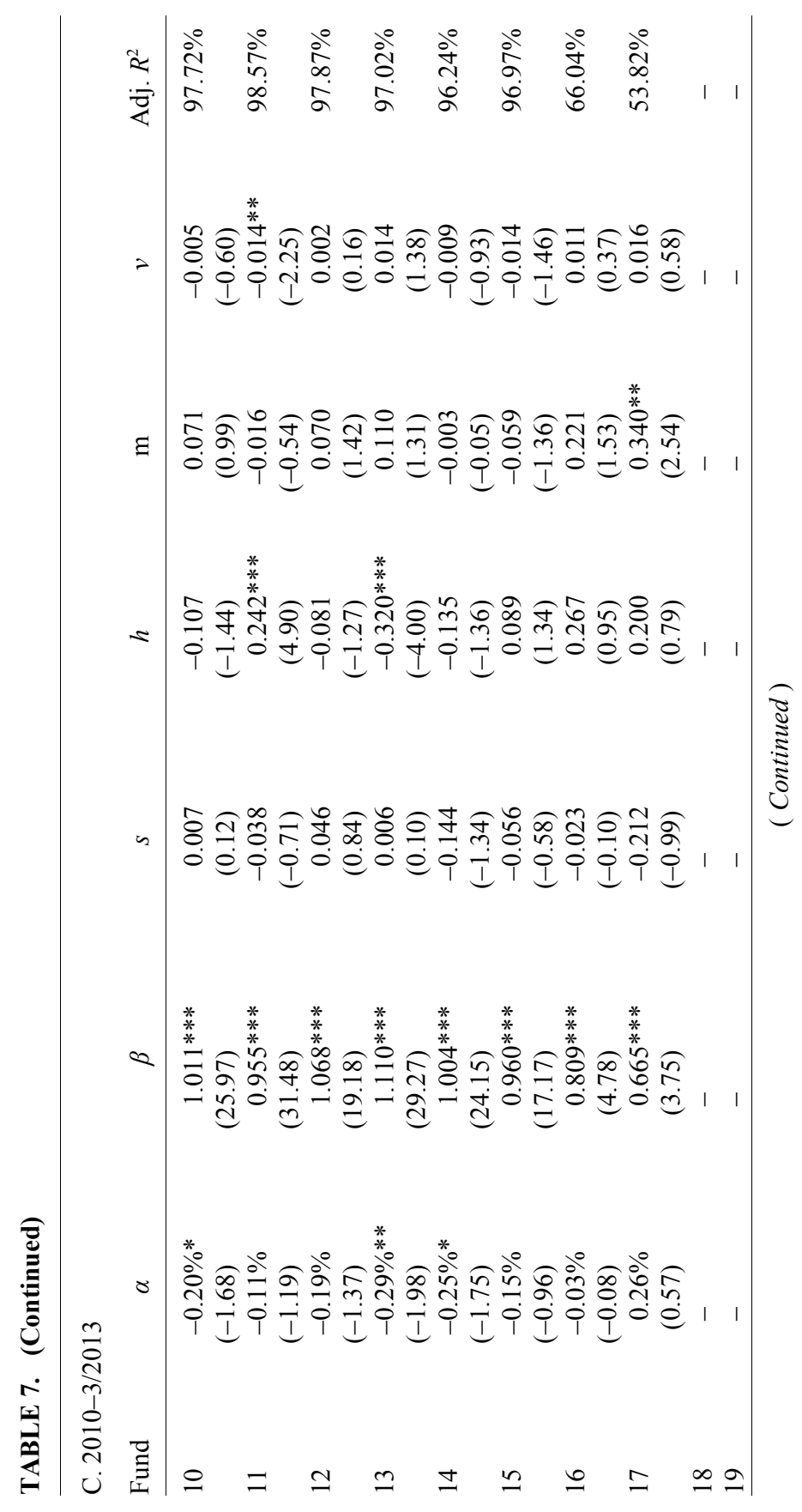




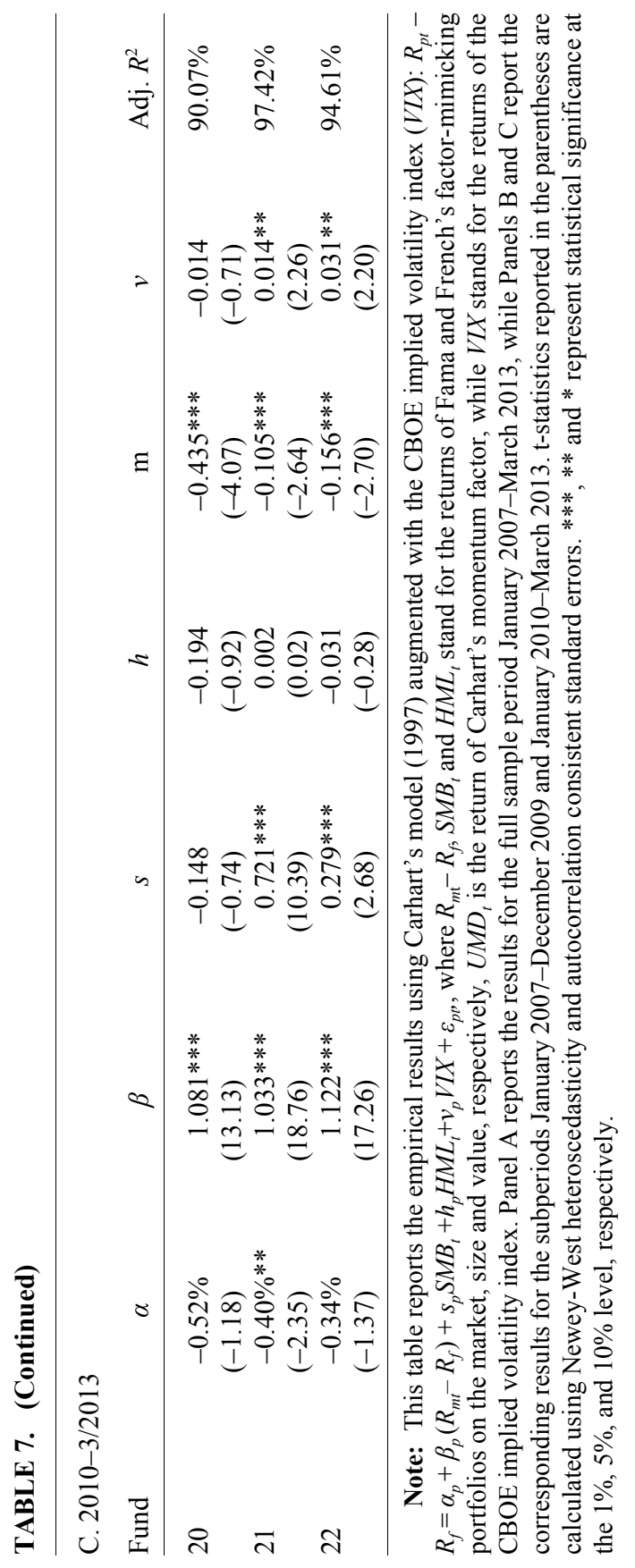




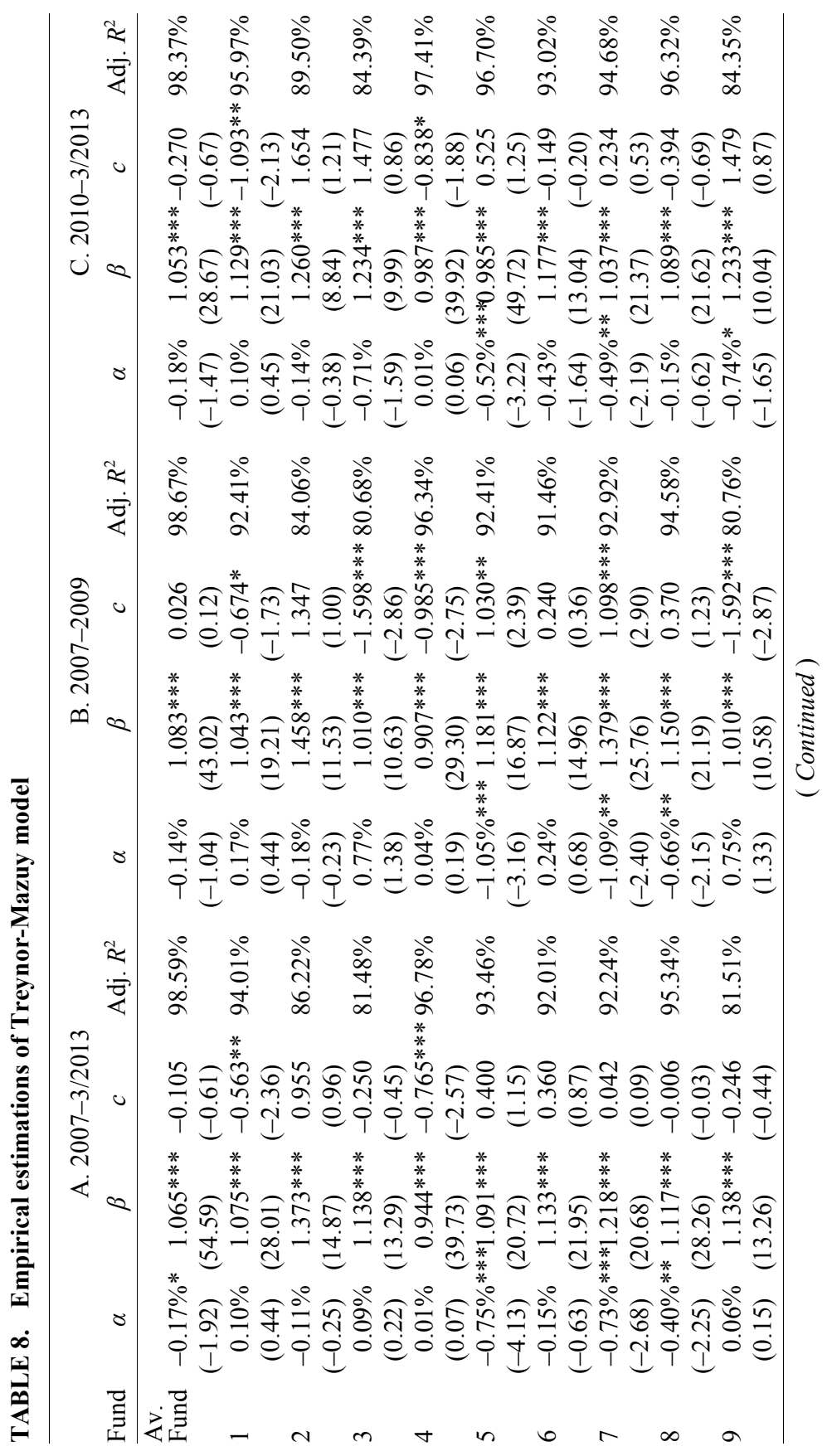




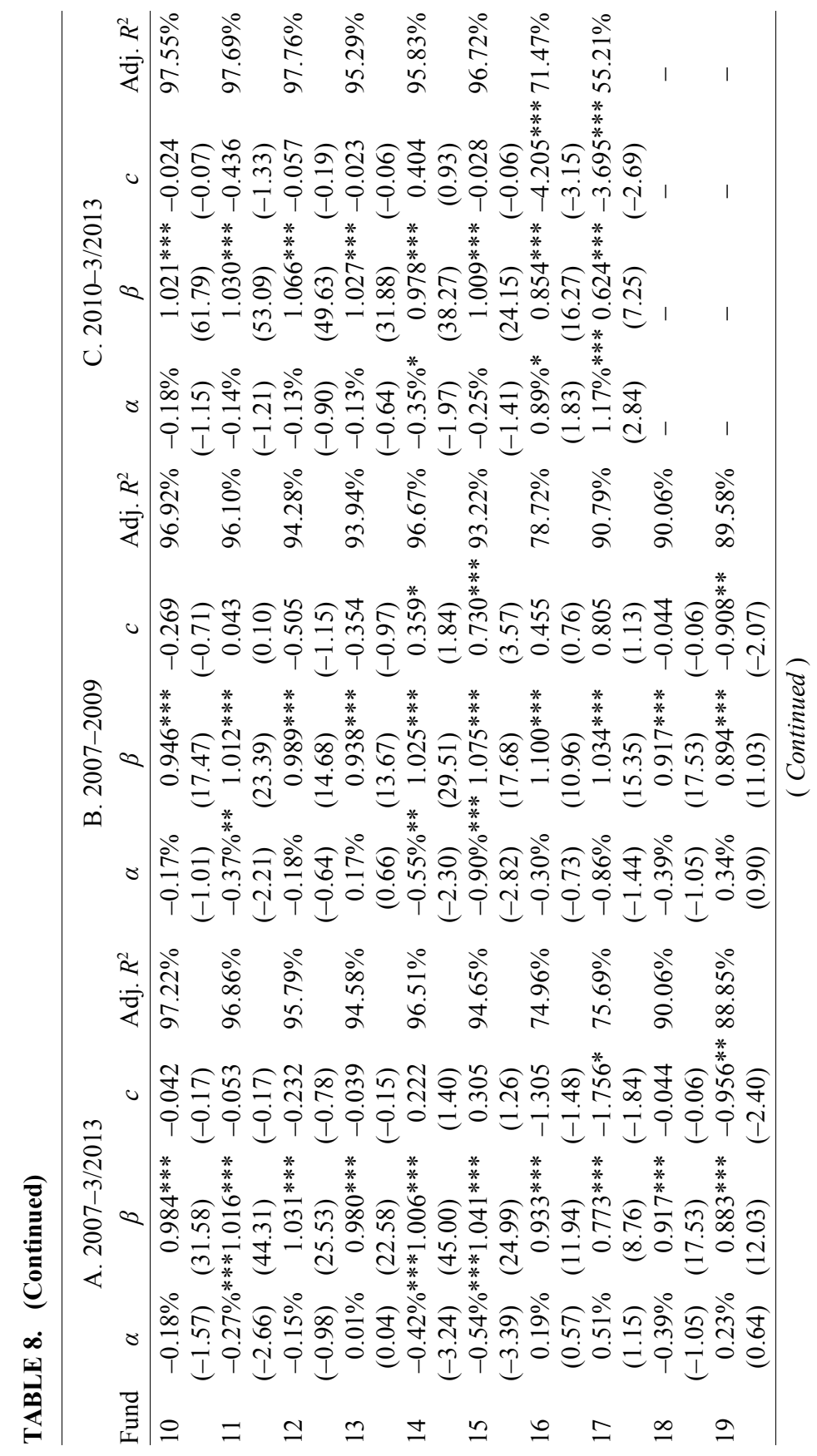




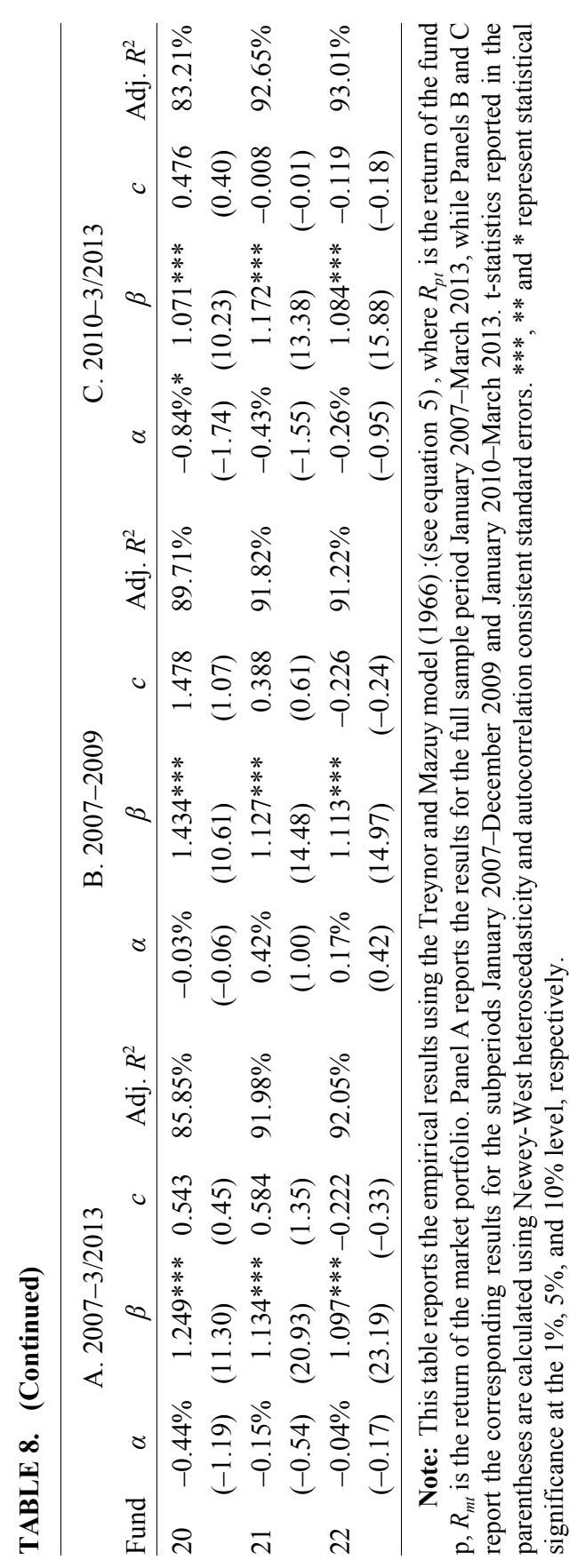




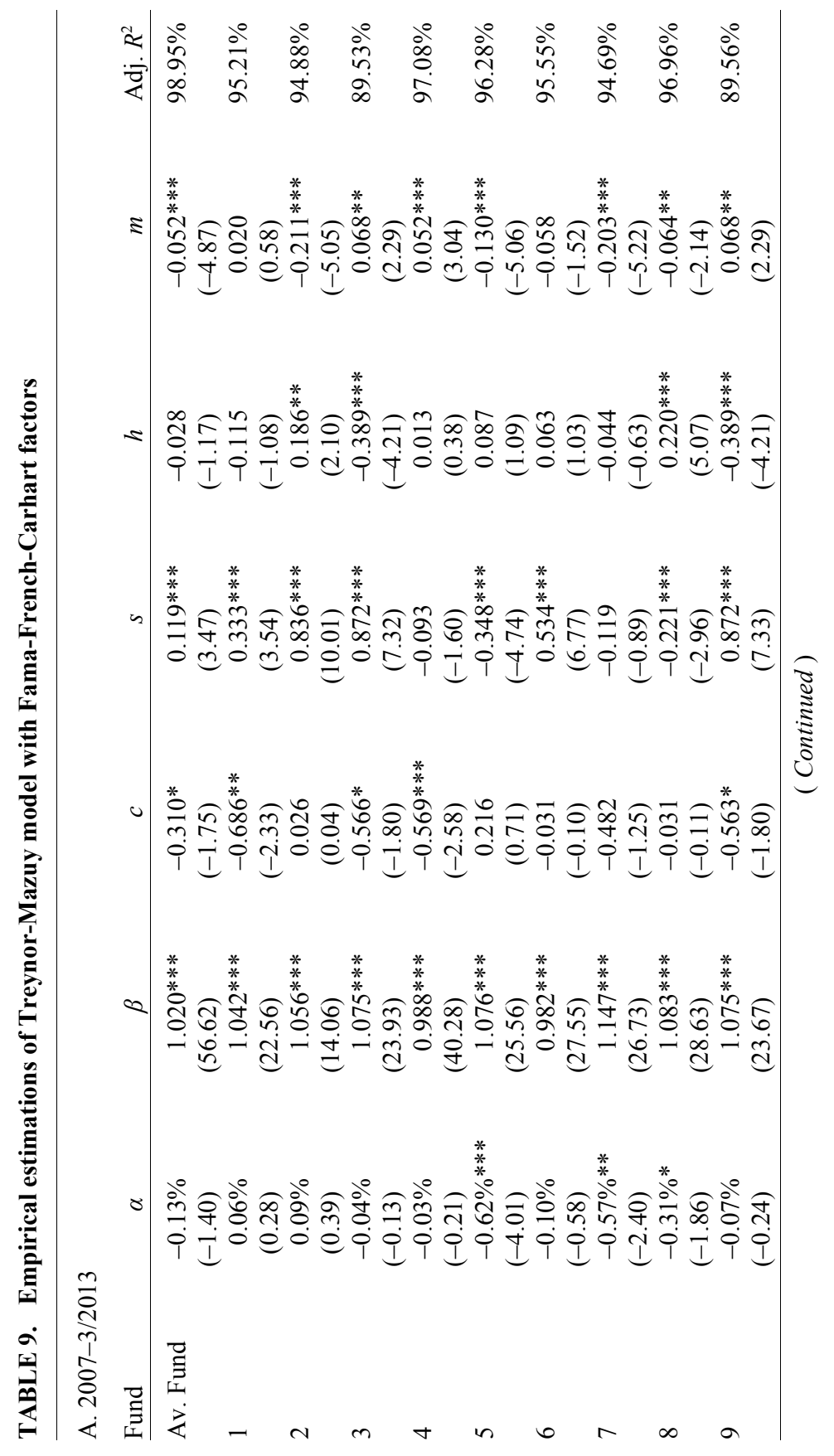




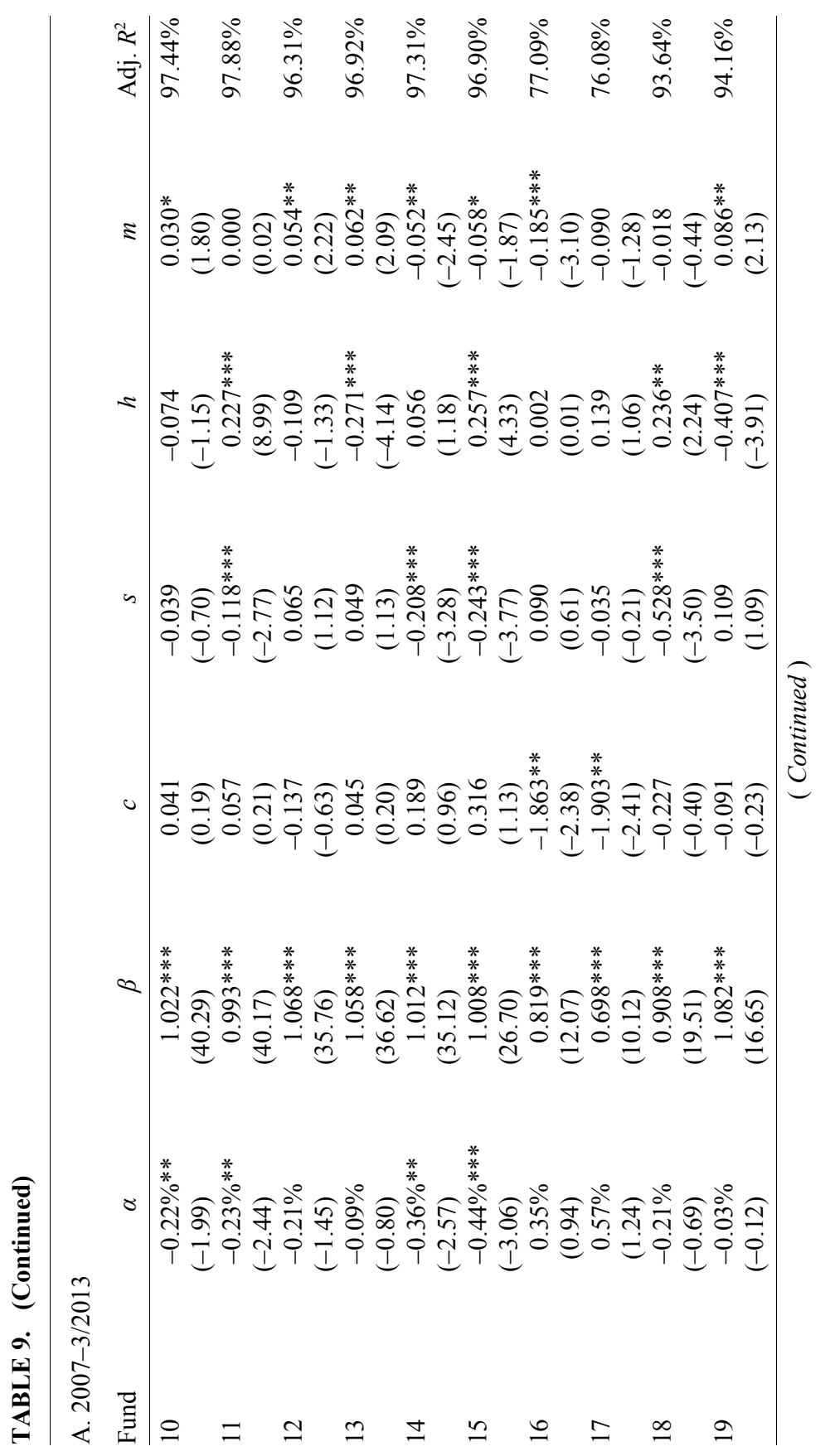




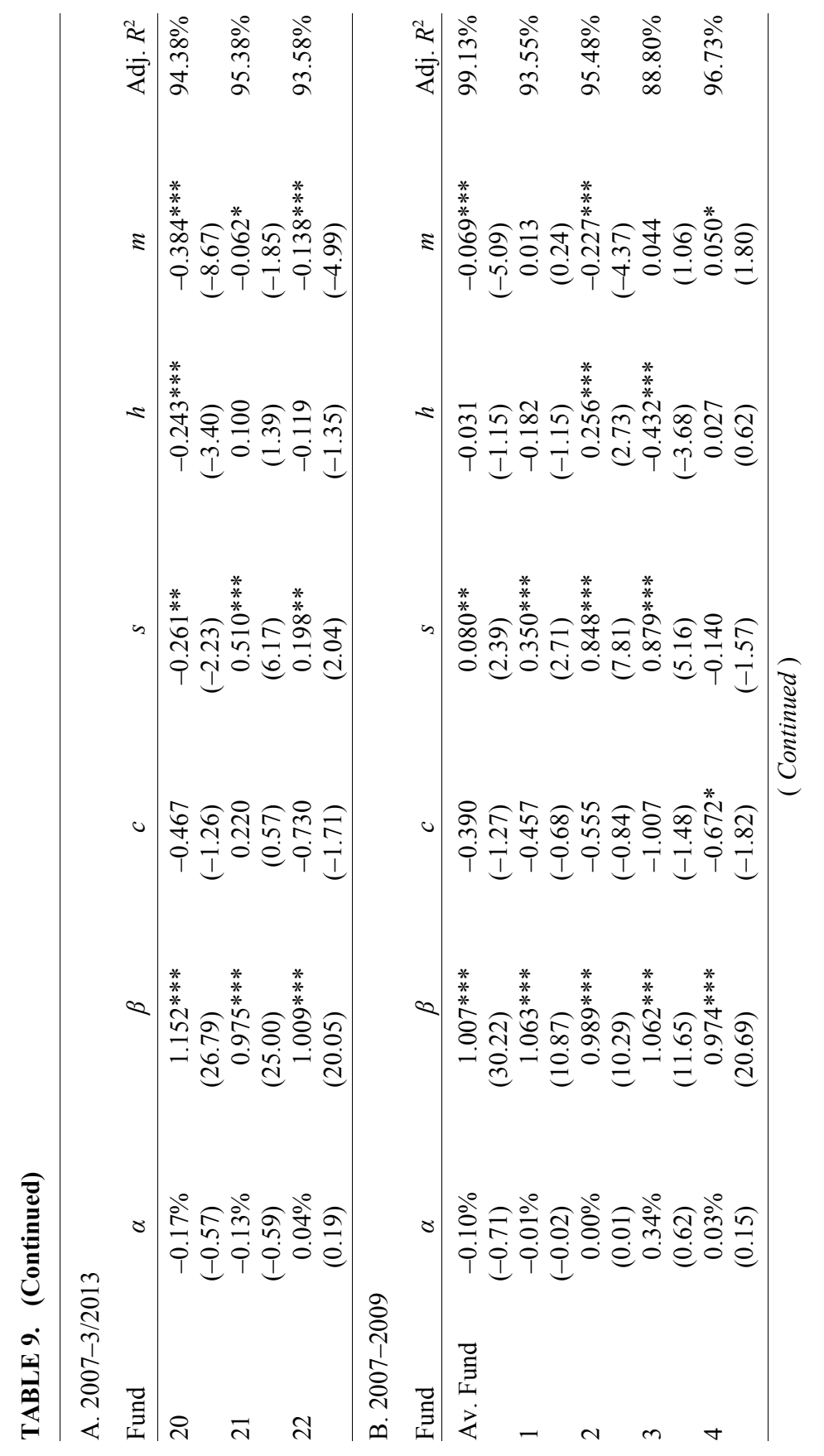




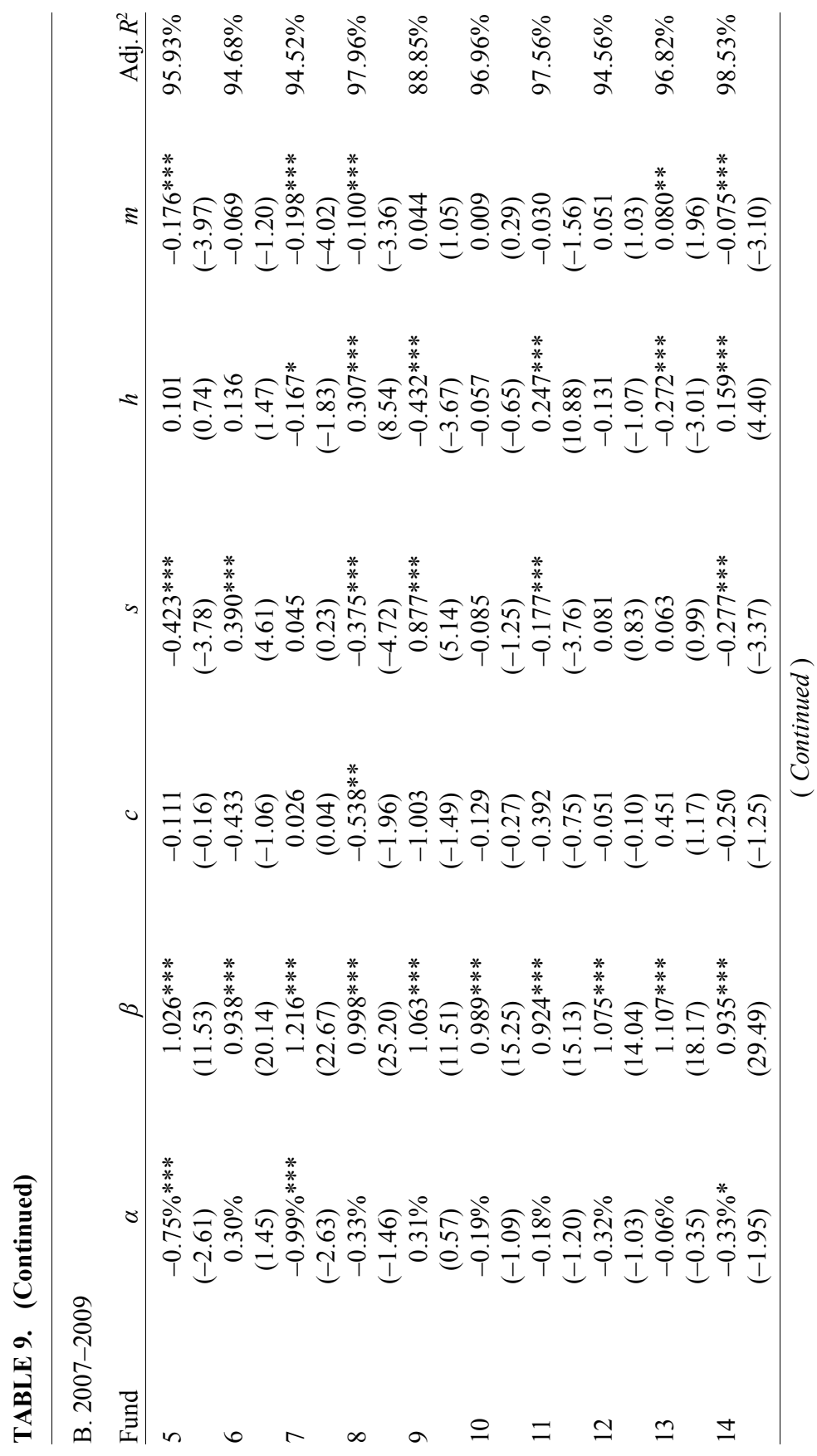




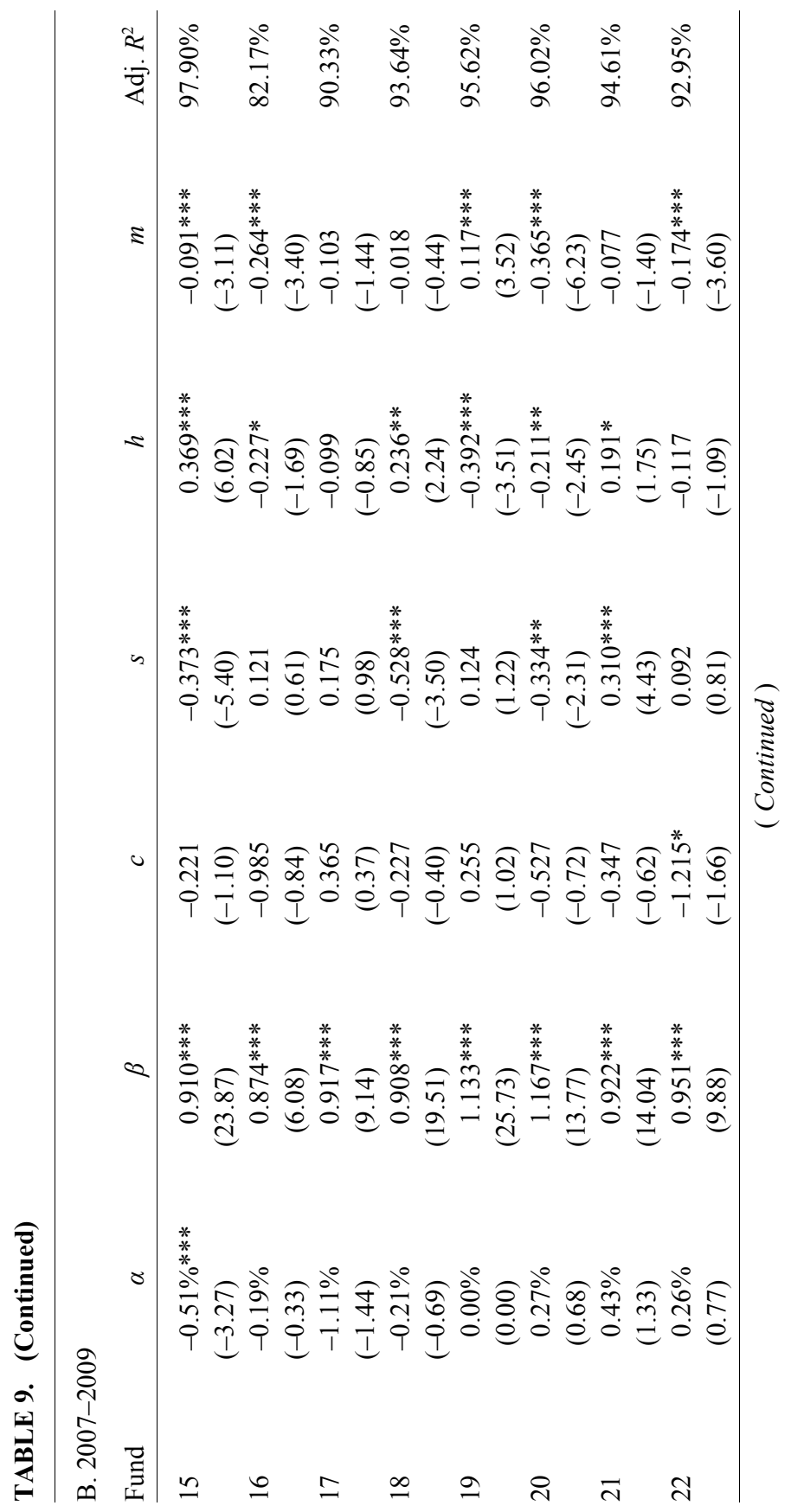




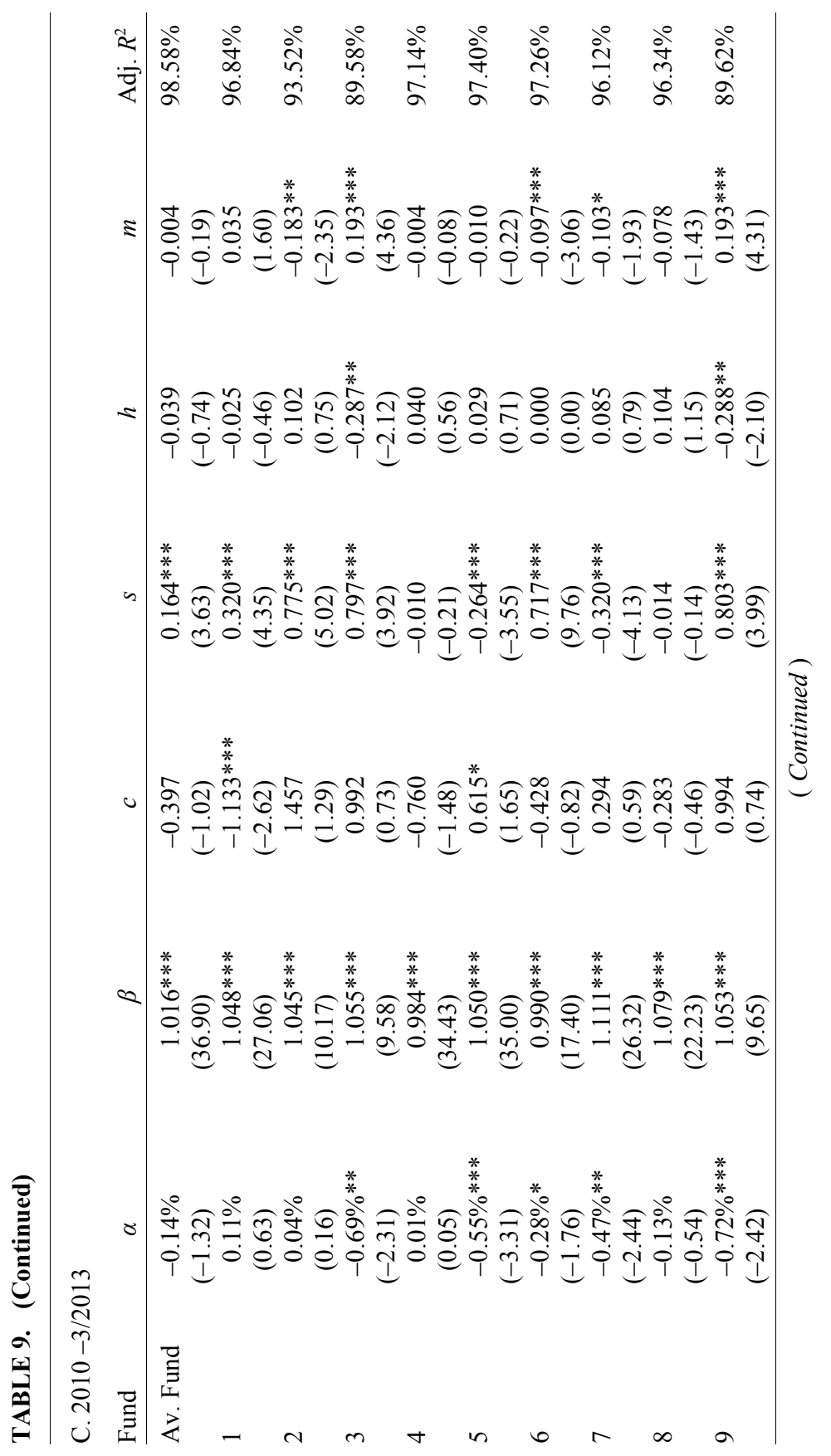




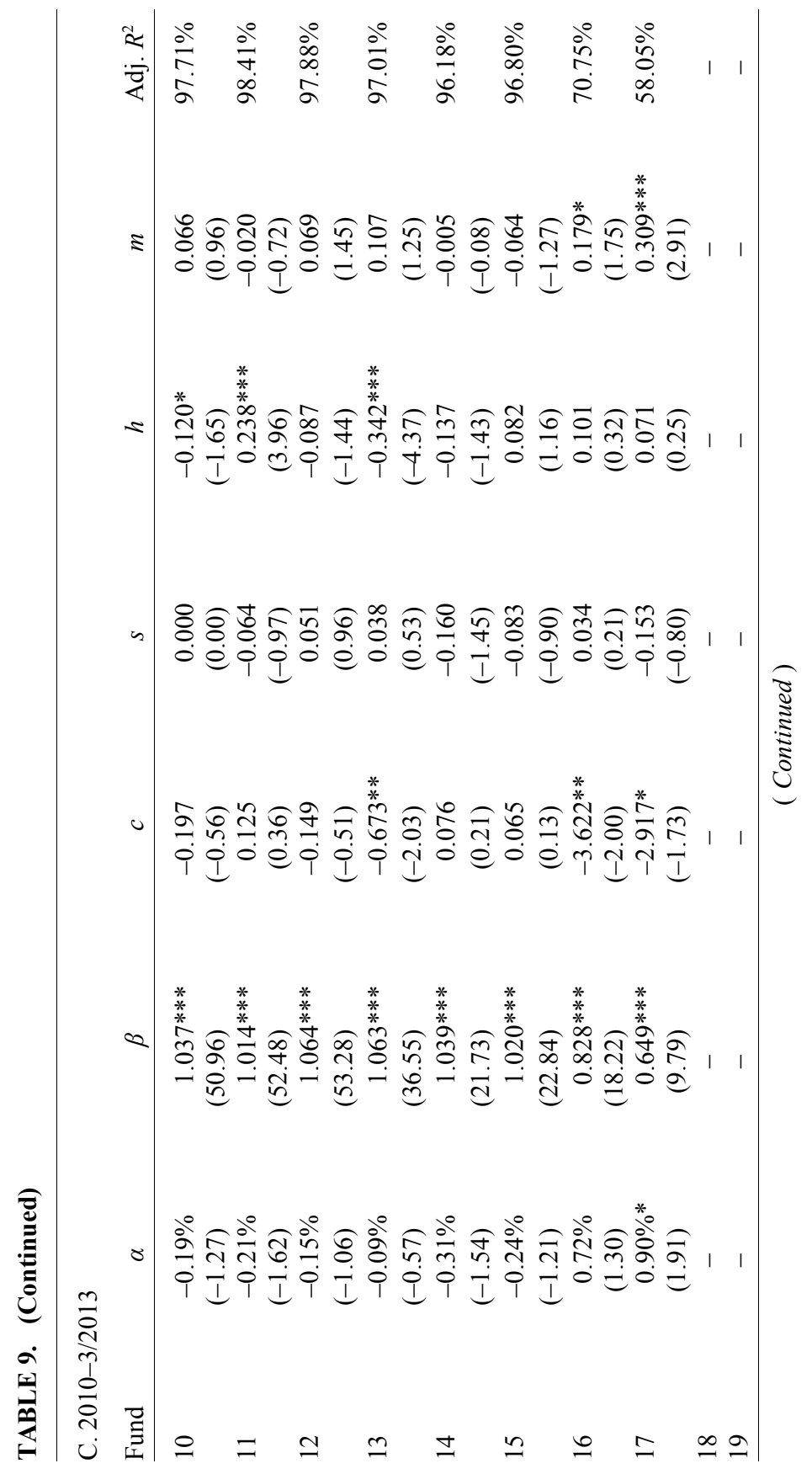




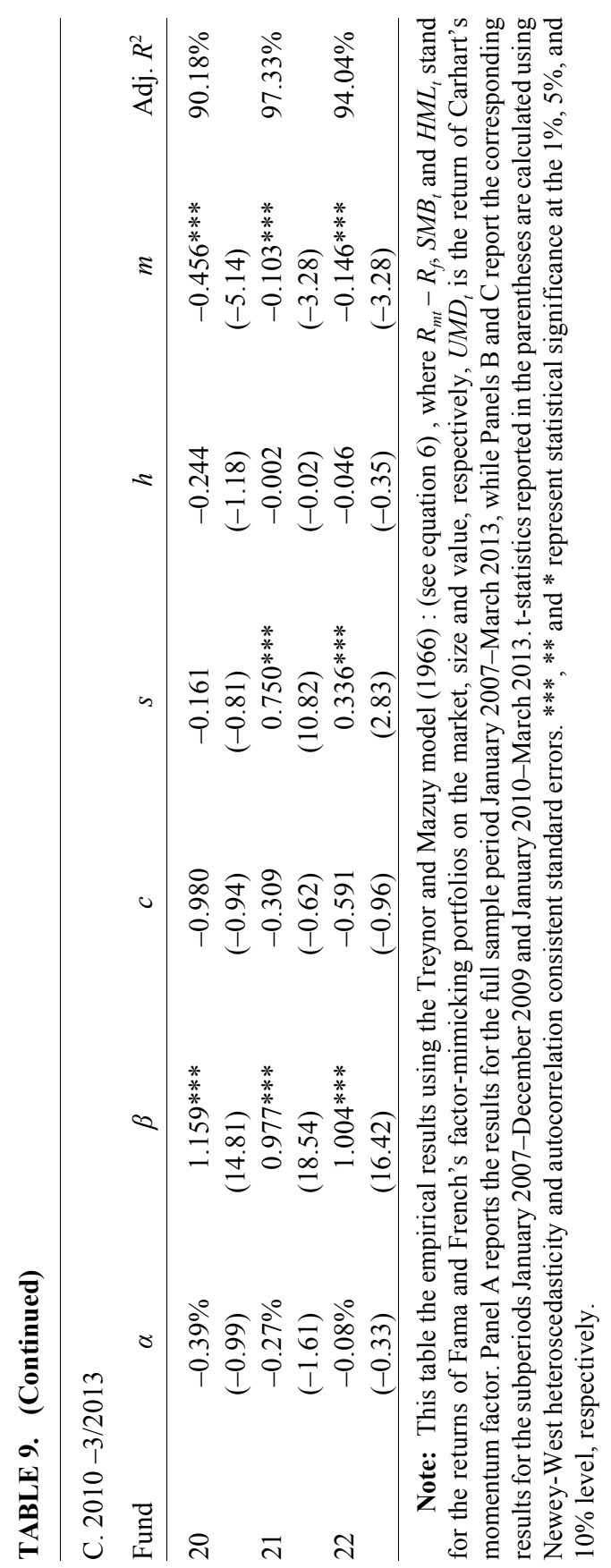




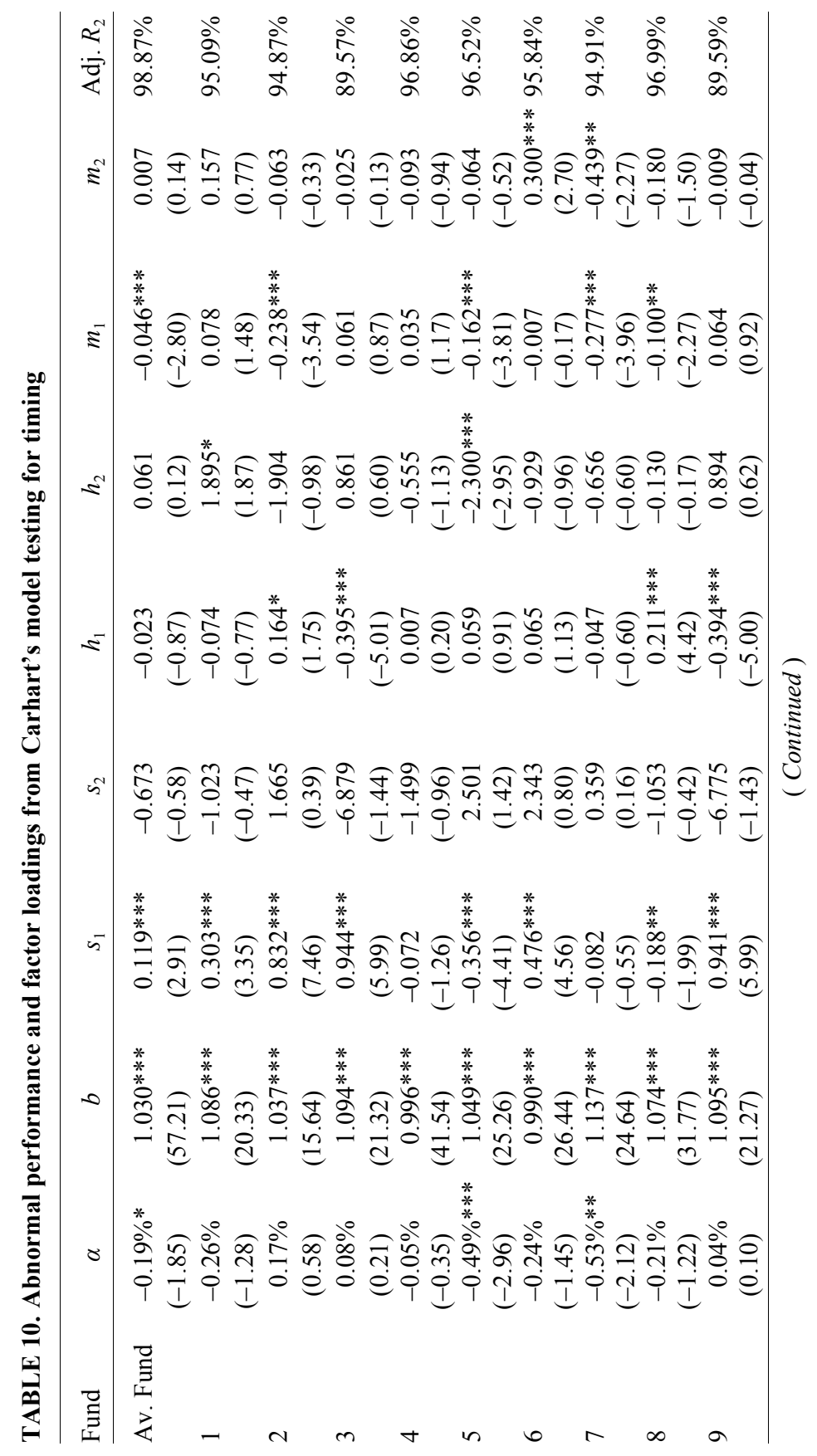




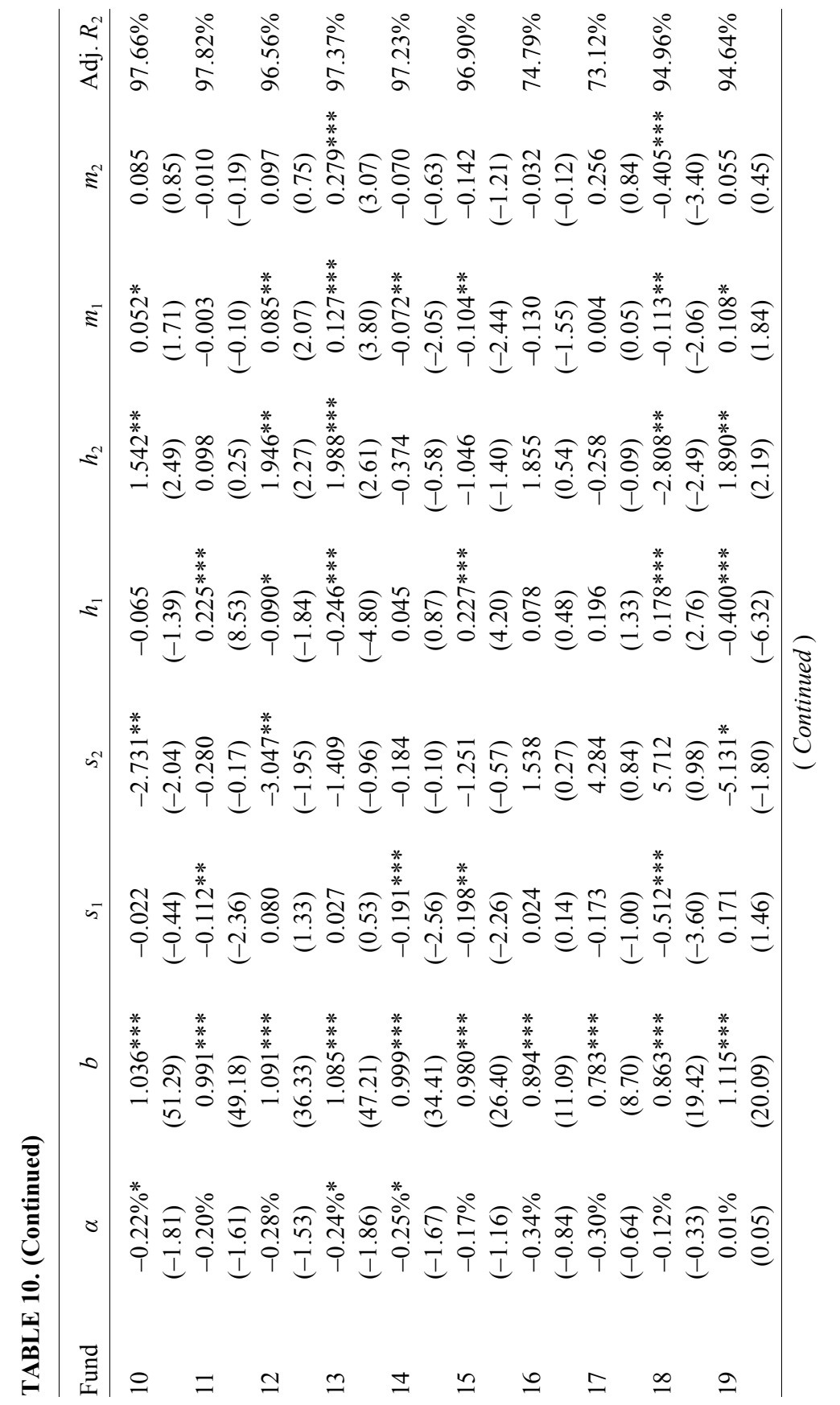




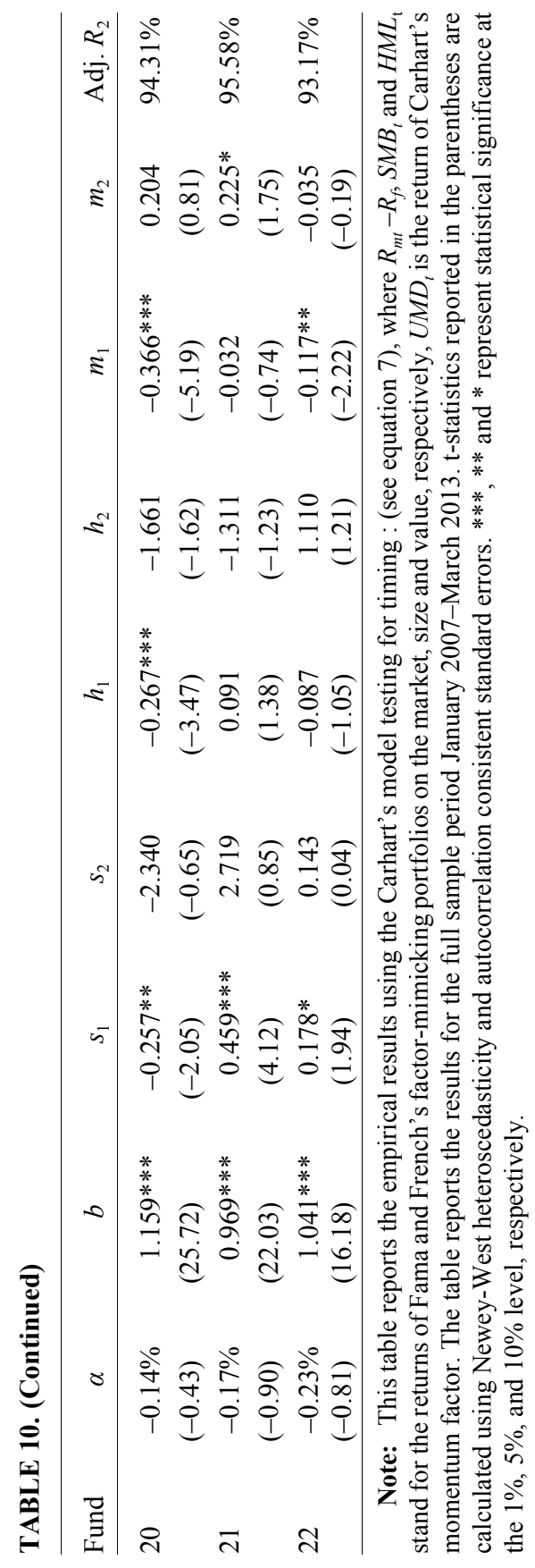


TABLE 11. Cross sectional analysis

\begin{tabular}{|c|c|c|c|c|c|}
\hline \multicolumn{6}{|l|}{ A. } \\
\hline \multicolumn{6}{|c|}{$a_{\text {Jensen }, p}=a+\beta$ Size $_{p}+c$ Age $_{p}+d$ Expense ratio $_{p}+e$ Mgr stated fee ${ }_{p}+\varepsilon$} \\
\hline$\alpha$ & $\beta$ & $c$ & $d$ & $e$ & Adj. $R_{2}$ \\
\hline $\begin{array}{l}-0.004 * * * \\
(-3.41)\end{array}$ & $\begin{array}{l}-0.001^{* * *} \\
(-4.75)\end{array}$ & $\begin{array}{l}0.0001 \\
(0.87)\end{array}$ & $\begin{array}{r}0.055 \\
(0.45)\end{array}$ & $\begin{array}{r}0.252 \\
(1.16)\end{array}$ & $45.67 \%$ \\
\hline \multicolumn{6}{|c|}{ B. } \\
\hline \multicolumn{6}{|c|}{$a_{\text {Carhart }, p}=a+\beta$ Size $_{p}+c$ Age $_{p}+d$ Expense ratio $_{p}+e$ Mgr stated fee $e_{p}+\varepsilon$} \\
\hline$\alpha$ & $\beta$ & $c$ & $d$ & $e$ & Adj. $R_{2}$ \\
\hline $\begin{array}{l}-0.003 * * * \\
(-2.36)\end{array}$ & $\begin{array}{l}-0.001^{* * *} \\
(-5.20)\end{array}$ & $\begin{array}{l}0.0001 \\
(1.32)\end{array}$ & $\begin{array}{c}0.008 \\
(0.09)\end{array}$ & $\begin{array}{r}0.032 \\
(0.19)\end{array}$ & $40.32 \%$ \\
\hline
\end{tabular}

Note: This table reports the empirical results for the cross-sectional regressions : (see equation in Panel A) and (see equation in Panel B), where we employ alphas (Jensen or Carhart) for the 20 funds that cover both subperiods. Size $e_{p}$ is the average fund size in billion USD for the whole period using monthly data, $A g e_{p}$ is the age of the fund since its inception (we have employed a maximum age of fifteen years), Expense ratiop is the total expense ratio of each individual fund and Mgr stated $f e e_{p}$ is the management stated fee of each individual fund .t-statistics reported in the parentheses are calculated using Newey-West heteroscedasticity and autocorrelation consistent standard errors. ${ }^{* * *}, * *$ and $*$ represent statistical significance at the $1 \%, 5 \%$, and $10 \%$ level, respectively.

no such evidence, also indicating that this timing ability was short-lived. For robustness, we have repeated this exercise by adjusting for size, value and momentum factors, estimating the augmented Treynor-Mazuy model specified in (6). The results reported in table 9 are very similar, with the addition that the previously reported positive timing ability during the crisis period has now disappeared. Overall, these results are in agreement with the evidence provided by Santoni and Kelshiker (2010), who find no significant evidence to support that behavioral funds can anticipate market reversals.

Furthermore, the results reported in the table 10 indicate little significant evidence of funds' timing ability with respect to the $S M B$, $H M L$ and MOM factors (Model 7). Only few funds exhibit significant ability with respect to the $H M L$ or MOM factor, but even among these funds, half of them exhibit negative rather than positive timing ability.

The final step in our analysis is to examine what fund characteristics affect their performance. To this end, we regress funds' Jensen alpha or, alternatively, Carhart alpha full sample estimates on their age, size(assets under management), management stated fee and total 


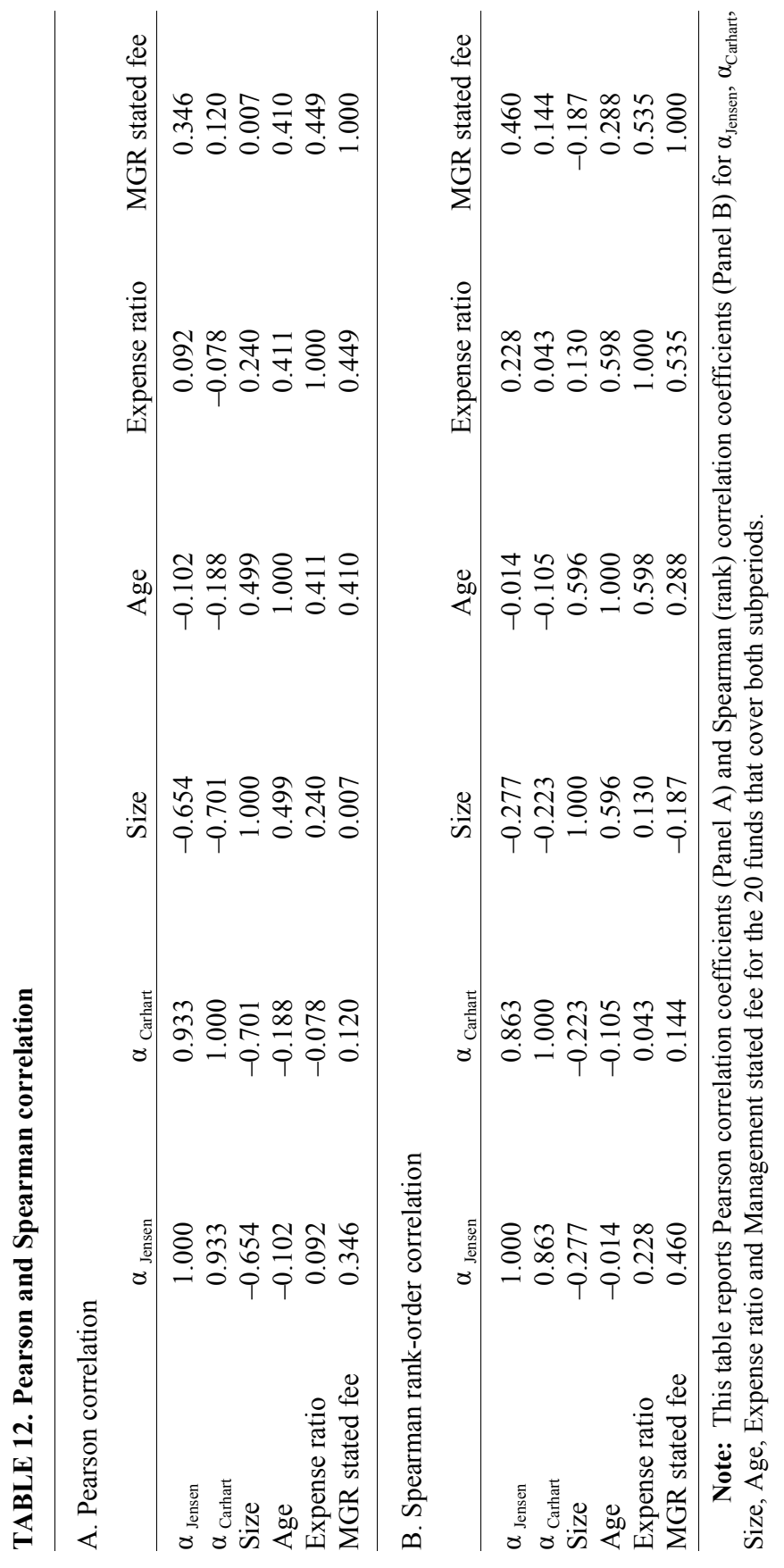


expense ratio. Results from this cross-sectional regression are reported in table 11. The only significant relationship found is the one between fund performance and size. This finding is consistent with the commonly stated assumption of decreasing returns to scale for fund performance (see, for example, Berk and Green, 2004; Alexakis and Tsolas, 2011 etc.). Since the cross-section of the examined funds is rather small, and hence we have very few degrees of freedom in the performed regression, we also report pairwise correlations between alphas (Jensen and Carhart) and each of these characteristics. In particular, we report in table 12 both Pearson correlation coefficients (panel A) and Spearman (rank) correlation coefficients (panel B). Again, the most notable and consistent relationship across the various measures appears to be the negative correlation between funds' performance and their size.

\section{Conclusion}

This paper examines the performance of US behavioral mutual funds during the recent financial crisis period and its aftermath, when market inefficiencies were more likely to lead to profitable trading strategies. Contributing to the limited prior literature on behavioral mutual funds (Wright et al., 2006, Reinhart and Brennan, 2007, and Santoni and Kelshiker, 2010), we use a series of raw as well as risk-adjusted performance measures to test whether behavioral mutual funds outperform their benchmark indices, market returns and passive mutual funds (index funds, ETFs).

The results indicate that there is no evidence of outperformance of behavioral funds versus the market return and respective benchmark indices on a risk-adjusted basis. To the contrary, we find that some funds significantly underperform their benchmarks both in economic and in statistical terms. Moreover, there is no evidence that these funds systematically follow size, value or momentum investment strategies. We also find no evidence to support the argument that these funds could time the market by suitably modifying their market exposure. To the contrary, a number of funds exhibited negative timing ability. Finally, when analyzing the determinants of funds' performance, we find a negative correlation with their size as measured by total assets under management. When detailed funds' stock holdings become available, a more detailed analysis could examine the particular investment 
strategies that these funds follow and whether these strategies exploit market inefficiencies for the benefit of funds' shareholders. We leave this issue for future research.

Accepted by: Prof. P. Theodossiou, Editor-in-Chief, June 2014

\section{References}

Alexakis, P., and Tsolas, I. 2011. Appraisal of mutual equity fund performance us-ing data envelopment analysis. Multinational Finance Journal 15: 273-296.

Babalos, V.; Philippas, N.; Doumpos, M.; and Zopounidis C. 2012. Mutual funds performance appraisal using stochastic multicriteria acceptability analysis. Applied Mathematics and Computation 218: 5693-5703.

Baker, M., and Wurgler, J. 2006. Investor sentiment and the cross-section of stock returns. Journal of Finance 61: 1645-1680.

Baker, M., and Wurgler, J. 2007. Investor sentiment and the stock market. Journal of Economic Perspectives 21: 129-151.

Berk, J., and Green, R. 2004. Mutual fund flows and performance in rational markets. Journal of Political Economy 112: 1269-1295.

Bogle, J. 2005. The Mutual Fund Industry 60 Years Later: For Better or Worse?. Financial Analysts Journal 61: 15-24.

Brown, G. W., and Cliff, M. T. 2005. Investor sentiment and asset valuation. Journal of Business 78: 405-440.

Brunnermeier, M. K. 2001. Asset Pricing under Asymmetric Information: Bubbles, Crashes, Technical Analysis and Herding. Oxford University Press.

Brunnermeier, M. K. 2009. Deciphering the Liquidity and Credit Crunch 2007-2008. Journal of Economic Perspectives 23: 77-100.

Brunnermeier, M. K., and Pedersen, L. H. 2009. Market Liquidity and Funding Liquidity. Review of Financial Studies 22: 2201-2238.

Carhart, M. M. 1997. On persistence in mutual fund performance. Journal of Finance 52: 52-82.

Constantinides, G. M. 1997. Transaction costs and the pricing of financial assets. Multinational Finance Journal 1: 93-99.

DeLong, J. B.; Shleifer, A.; Summers, L. H.; and Waldmann, R. J. 1990. Noise Trader Risk in Financial Markets. Journal of Political Economy 98: 703-738.

Elton, E. J.; Gruber, M. J.; and Blake, C. R. 2012. An examination of mutual fund timing ability using monthly holdings data. Review of Finance 16: 619-645.

Fama, E. F., and French K. R. 2010. Luck versus Skill in the Cross-Section of 
Mutual Fund Returns. Journal of Finance 65: 1915-1947.

Gromb, D., and Vayanos, D. 2010. Limits of Arbitrage: The State of the Theory. Annual Review of Financial Economics 2: 251-275.

Jensen, M. 1968. The performance of mutual funds in the period 1945-64. Journal of Finance 23: 389-416.

Kousenidis, D., and Negakis, C., 2012. The Underperformance of Young Closed-End Funds in Greece. Multinational Finance Journal, forthcoming.

Kumar, A., and Lee, C. M. C. 2006. Retail investor sentiment and return comovements. Journal of Finance 61: 2451-2486.

Philippas, N., and Tsionas, E. 2002. Performance Evaluation: A Review Article and an Empirical Investigation of Greek Mutual Fund Managers. The International Business and Economics Journal 1: 31-44.

Reinhart, W. J., and Brennan, M. 2007. Behavioral Portfolios Performance Measurement. Financial Decisions 19: 1-15.

Santoni, A., and Kelshiker, A. R. 2010. Behavioral Finance: An Analysis of the Performance of Behavioral Finance Funds. The Journal of Index Investing 1: 56-72.

Sharpe, W. F. 1966. Mutual fund performance. Journal of Business 39: $119-138$.

Shefrin, H. 2000. Beyond Greed and Fear: Understanding Bahavioral Finance and the Psychology of Investing, Oxford University Press.

Shin, H. S. 2010. Risk and Liquidity. Clarendon Lectures in Finance, Oxford University Press.

Tabner, I. T. 2009. Benchmark Concentration: Capitalization Weights Versus Equal Weights in the FTSE 100 Index. Multinational Finance Journal 13: 209-228.

Treynor, J. 1965. How to rate management of investment funds. Harvard Business Review 43: 63-75.

Treynor, J., and Mazuy, K. 1966. Can mutual funds outguess the market? Harvard Business Review 44: 131-136.

Wermers, R. 2000. Mutual Fund Performance: An Empirical Decomposition into Stock-Picking Talent, Style, Transactions Costs, and Expenses. Journal of Finance 55: 1655 - 1695.

Wright, C.; Banerjee, P.; and Boney, V. 2006. Behavioral Finance: Are the Disciples Profiting from the Doctrine? The Journal of Investing 17: 82-90 (2008). 